\title{
La série céramique du Bronze final II/III du site du Petit Souper à Saint-Hilaire-Saint-Florent (Maine- et-Loire)
}

The Ceramic Series of Final Bronze II/III of the Site of Petit Souper, Saint-HilaireSaint-Florent (Maine-et-Loire)

\section{Roland Le Guévellou}

\section{OpenEdition Journals}

Édition électronique

URL : https://journals.openedition.org/rao/1558

DOI : $10.4000 /$ rao.1558

ISBN : 978-2-7535-1846-9

ISSN : 1775-3732

Éditeur

Presses universitaires de Rennes

Édition imprimée

Date de publication : 31 décembre 2011

Pagination : 37-70

ISBN : 978-2-7535-1844-5

ISSN : 0767-709X

Référence électronique

Roland Le Guévellou, "La série céramique du Bronze final II/III du site du Petit Souper à Saint-HilaireSaint-Florent (Maine-et-Loire) », Revue archéologique de l'Ouest [En ligne], 28 | 2011, mis en ligne le 30 mars 2014, consulté le 22 août 2022. URL : http://journals.openedition.org/rao/1558 ; DOI : https:// doi.org/10.4000/rao.1558 


\title{
La série céramique du Bronze final II/III du site du Petit Souper à Saint-Hilaire-Saint-Florent (Maine-et-Loire)
}

\author{
The Ceramic Series of Final Bronze II/III of the Site of Petit Souper, \\ Saint-Hilaire-Saint-Florent (Maine-et-Loire)
}

\author{
Roland Le GuÉvellou*
}

\begin{abstract}
Résumé : La fouille du site du Petit Souper à Saint-Hilaire-Saint-Florent (Maine-et-Loire), réalisée au mois de janvier 2008 par une équipe de l'Inrap sous la responsabilité scientifique de Y. Viau (Viau et al., 2008), a mis au jour une série de structures fossoyées contenant de nombreux fragments de céramiques attribuables à la fin de la phase ancienne et à la phase moyenne du Bronze final. Ce site d'habitat est établi au bord d'un plateau dominant la Loire, en surplomb du site du Bronze final de l'Alleu, fouillé par le Docteur Gruet à la fin des années 1970. Le corpus céramique Bronze final II/III du Petit Souper constitue à ce jour le référentiel le plus documenté pour la région des Pays-de-la-Loire. En outre, la fouille a fourni une importante série lithique associée à ce contexte. Ce site est le point le plus occidental de la diffusion de la céramique de tradition RSFO le long de l'axe ligérien, vecteur majeur de diffusion des cultures, voire aire d'identité culturelle.
\end{abstract}

\begin{abstract}
The excavation of the site of thePetit Souper at Saint-Hilaire-Saint-Florent (Maine-et-Loire), realized in the month of January 2008 by a team of Inrap under the scientific responsibility of Y. Viau (Viau et al., 2008), put at the day a series of trenched structures container of many ceramics fragments ascribable at the end of the old phase and the average phase of final Bronze. This site of habitat is established at the edge of a plate dominating the Loire, in overhang of the site of the Later Bronze, l'Alleu, excavated by Doctor Gruet at the end of the years 1970. The ceramic corpus Bronzes final IIIIII of the Petit Souper to date constitutes the reference frame more documented for the area of the Pays-de-la-Loire. Moreover, the excavation provided an important lithic series associated with this context. This site is the most Western point of the diffusion of the ceramics of tradition RSFO along the axis ligérien, vector major of diffusion of the cultures, even surface of cultural identity.
\end{abstract}

Mots clé : Bronze final, céramique, RSFO, fosses, Loire.

Keywords: Later Bronze Age, ceramic, RSFO, pits, Loire.

Au mois d'octobre 2006, un diagnostic réalisé par Martin Pithon (Inrap) (Pithon, 2006) sur la commune de SaintHilaire-Saint-Florent (Maine-et-Loire, fig. 1), au lieu-dit le Petit Souper révèle la présence, en bordure d'un plateau surplombant la vallée de la Loire, de plusieurs fosses contenant des fragments de céramiques attribuables à l'étape moyenne du Bronze final.
La fouille, engagée en janvier 2008, sous la responsabilité scientifique de Yann Viau (Inrap Pays de la Loire) s'est traduite par un décapage ciblé de $1000 \mathrm{~m}^{2}$ qui a révélé la présence de plusieurs fosses et trous de poteaux (Viau et al., 2008). Le mobilier recueilli dans ces structures représente, quantitativement, la série du Bronze final II/III la plus

*INRAP Grand-Ouest, centre de Carquefou - 1 impasse de la Perrière, 49270 LE FUILET. (roland.le-guevellou@inrap.fr) 


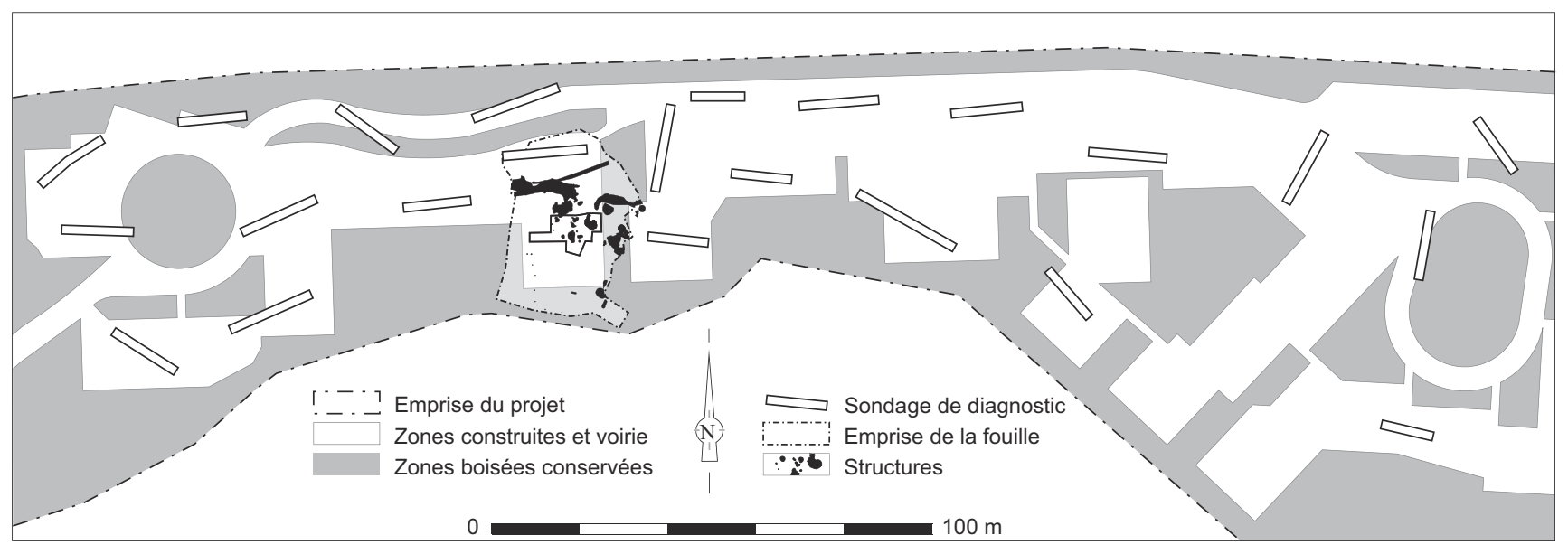

Figure 1: Le Petit Souper, plan du diagnostic et de la fouille (DAO : H. Hostein).

Figure 1: Le Petit Souper, plan of the diagnosis and the excavation (DAO: H. Hostein).

conséquente trouvée à ce jour, en contexte archéologique, dans le quart nord-ouest de la France.

Cet ensemble céramique permet surtout la redécouverte de ce faciès occidental de l'étape moyenne du Bronze final à Saint-Hilaire-Saint-Florent, déjà connu pour le site de l'Alleu mis en évidence par le Docteur Michel Gruet. Il faut ici évoquer cet épisode : au mois d'août 1977, le Docteur M. Gruet et son équipe, effectuaient une fouille de sauvetage au lieu-dit l'Alleu à Saint-Hilaire-Saint-Florent près de Saumur, sur les rives de la Loire. La construction d'un lotissement y avait révélé la présence d'un habitat attribué au Bronze final II. L'intervention archéologique a « consisté en l'étude des coupes de tranchée (liées aux travaux de voirie), de diverses traces d'habitation et à la fouille d'un fossé dépotoir" (L'Helgouach, 1979, p. 569). Le caractère d'urgence de cette opération et les mauvaises conditions d'intervention n'ont, malheureusement, pas permis à l'équipe de fouille d'étudier sereinement le site. Le geste archéologique s'est surtout traduit par un ramassage de mobilier. Par la suite, A. Braguier a dessiné les formes et décors des poteries récoltées. La somme de dessins réunit près de 130 planches présentant de très nombreux profils et décors attribuables au style Rhin-Suisse-France-Orientale. Le considérable lot céramique du site de l'Alleu se réduit donc à un recueil typologique déconnecté de son contexte d'origine. Un aperçu de cette collection a été présenté par T. Nicolas en 2007 (Nicolas, 2007).

La fouille du site du Petit Souper offre donc l'occasion de décrire le Bronze final II/III de Saint-Hilaire-Saint-Florent et son contexte archéologique.

La série céramique se compose de 1698 fragments de céramique, pour un nombre minimum d'individus de 245 vases. Deux datations C14 ont pu être effectuées sur des prélève- ments de charbons issus des fosses 37 et 62 (fig. 3), elles inscrivent leur horizon chronologique vers la fin du Bronze final II a et au début du Bronze final II b. Le mobilier issu des fosses 37, 43 et 62 est attribuable à cette période. Ce travail de comparaison a également mis en évidence une seconde phase d'occupation un peu plus tardive datée du Bronze final II b/III a (ensemble 41, fosses 67/68 et 38).

\section{LE CONTEXTE ARCHÉOLOGIQUE}

Le site du Petit Souper est installé sur le bord d'un plateau surplombant la vallée de la Loire. Situé, en moyenne, à $80 \mathrm{~m}$ d'altitude, ce relief domine, d'une cinquantaine de mètres, la rive gauche du fleuve. Au pied de ce promontoire, soit à $200 \mathrm{~m}$ du site, se développe le lotissement de l'Alleu (fig. 2), à l'emplacement des découvertes du Dr Gruet en 1977.

Le substrat géologique est composé de sables et grès à spongiaires de texture argileuse. Les structures archéologiques ont été détectées sous 40 à $60 \mathrm{~cm}$ de terre végétale. Une trentaine de creusements, dont un fossé et ce qui pourrait être un chemin, témoignent de l'occupation protohistorique de ce bord de plateau. Hormis les vestiges liés à l'occupation du Bronze final, quatorze pièces de silex sont attribuables au Paléolithique moyen. Une hachette-pendeloque en éclogite découverte en surface de la fosse 37 (structure du Bronze final) relève typologiquement de la culture matérielle du Néolithique. Enfin, le profil d'un vase non décoré découvert dans le fossé 25 évoque le style campaniforme.

33 creusements ont été mis en évidence (fig. 3) : 9 fosses complexes, 6 fosses simples et 18 trous de poteaux. Il faut ajouter un fossé protohistorique (F 74) et ce qui a été 
Figure 2 : Le Petit Souper, plan de localisation topographique des sites du Petit Souper et de L'Alleu (DAO : H. Hostein). Figure 2 : Le Petit Souper, topographic plan of localization of the sites of Petit Souper and L'Alleu (DAO : H. Hostein).

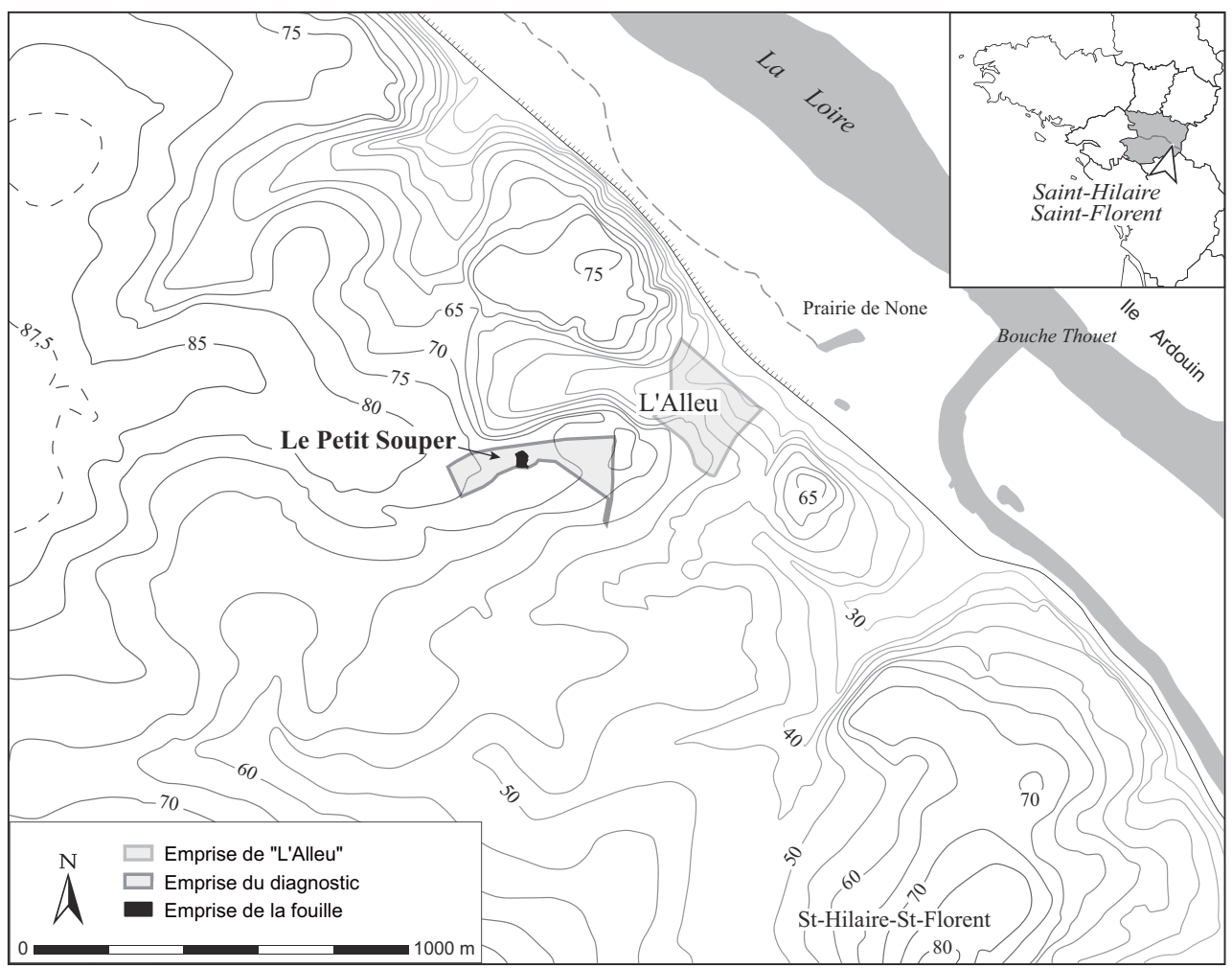

interprété comme un axe de cheminement (F 25/48/49). Cet axe de cheminement ne semble pas lié à l'occupation du Bronze final puisqu'il recoupe la fosse 67 attribuée à cette période. Par ailleurs, il s'avère postérieur au fossé 74 qui a, quant à lui, livré quelques tessons de facture protohistorique (Bronze final?) ainsi qu'une dizaine de grammes de scories de nature indéterminée (cuivre, fer?).

La nature des rejets découverts (céramique, silex, ossements de faune brûlés, fragments de pesons, parois de four, morceaux de meules) permet de considérer ce gisement comme un site d'habitat en bord de plateau. Cependant, l'étude des restes osseux réalisée par E. Cabot (Inrap) livre une information étonnante (cf. annexe 1). Des restes brûlés d'origine humaine, présents en faible quantité (24 grammes) ont été découverts dans les fosses 41, 44, 84, 90. De la même façon, 6 fosses $(14,27,37,62,88,91)$ contenaient des os brûlés de faune. Onze fosses ont donc livré des os brûlés soit d'origine animale, soit d'origine humaine, mais aucune structure ne contenait les deux types d'ossements en association. Sur la question des os humains, la conclusion de l'analyse anthropologique suggère que " malgré la faiblesse de l'échantillon pour ces dépôts, il semble bien y avoir là un geste spécifique et une volonté d'isoler ces restes humains ". Selon cette étude, les restes proviendraient d'individus adultes pour les trois premières fosses ( $\mathrm{F} 41, \mathrm{~F} 44$, F 84); par contre, les fragments d'os recueillis dans la fosse
90 (ensemble 41) sont attribués à un individu immature. Par ailleurs, l'étude établit une distinction entre la puissance de crémation des os humains (plusieurs heures à une température de $600^{\circ}$ à $900^{\circ}$ ) et le moindre niveau d'exposition à la chaleur des fragments de faune, "juste chauffés ", ce qui tendrait à considérer ces derniers comme restes culinaires. Il faut, dès à présent, remarquer que la distinction très nette établie par E. Cabot entre les structures contenant des os de faune et celles ayant restituées des restes humains correspond, en fait, aux activités respectives liées aux deux phases d'occupation.

Cette présentation du contexte archéologique doit également évoquer les conclusions de l'analyse des pièces lithiques (étude réalisée par P. Forré, Inrap, intégrée au rapport final d'opération : Viau, 2008).

217 pièces lithiques ont été extraites des structures. Quatorze d'entre elles sont attribuées au paléolithique moyen; cette attribution chronologique est fondée sur l'identification d'un nucléus et de 2 éclats de tradition Levallois. Pour l'ensemble du Bronze final, l'essentiel de la série lithique est constitué d'éclats de toutes tailles, pour certains retouchés. La part de l'outillage est très faible et se résume en tout et pour tout à un grattoir et un burin. L'analyse de P. Forré met l'accent sur le caractère opportuniste de cette industrie qui utilise des matériaux récoltés dans un rayon d'une quinzaine de kilomètres, les supports 


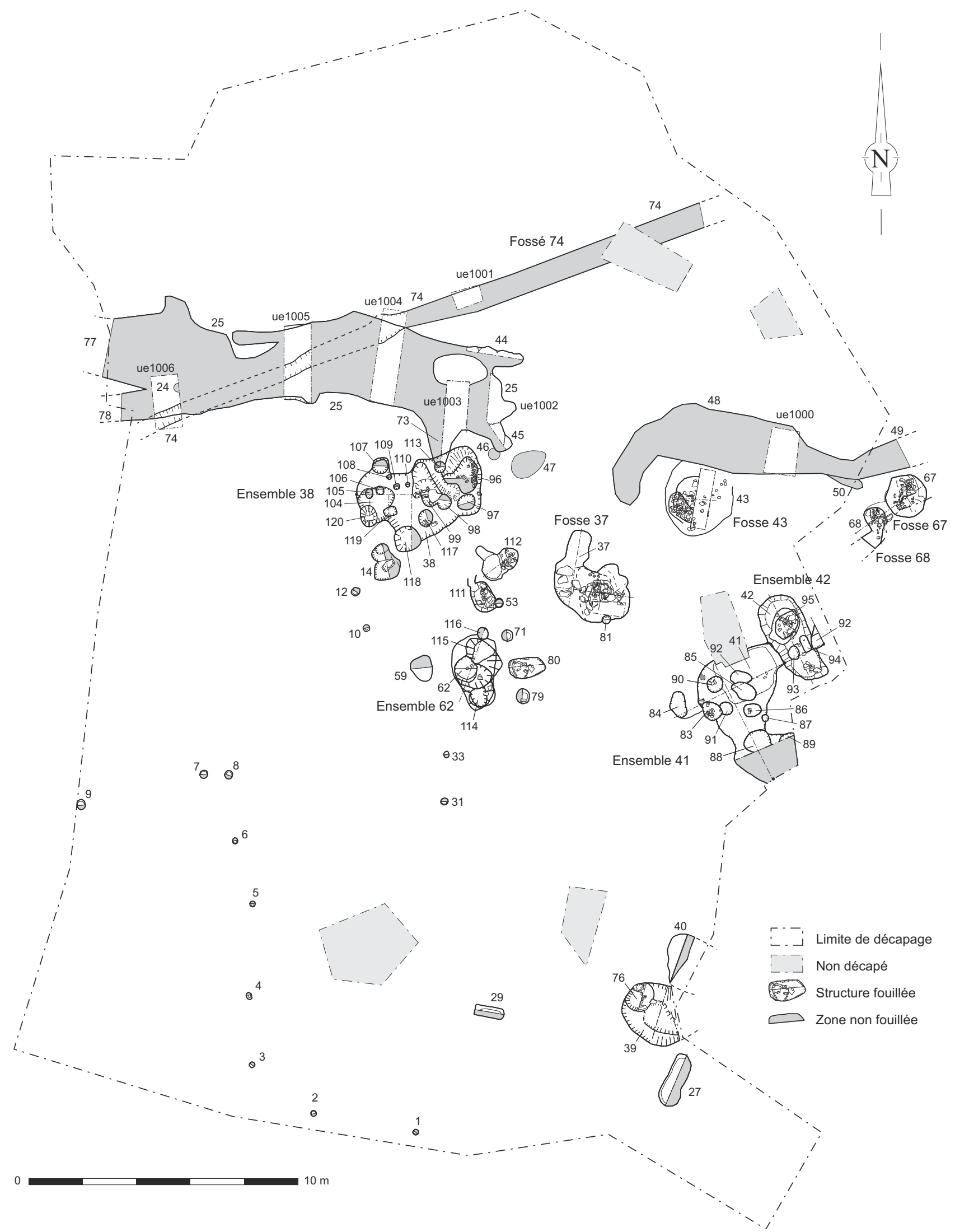

Figure 3 : Le Petit Souper, plan de la fouille (DAO : H. Hostein).

Figure 3: Le Petit Souper, plan of the excavation (DAO : H. Hostein). 
de débitage étant de qualité aléatoire. Les ressources locales de grès siliceux de plus ou moins bonne qualité sont mises à contribution dans le cadre d'une production non standardisée d'éclats.

\section{DesCription DES PRINCIPALES STRUCTURES (F 37, ENSEMBLE F 41, F 43, F 67, F 68, F 62)}

Les six structures retenues dans cette sélection rassemblent près de $89 \%$ des tessons attribuables à l'étape moyenne du Bronze final (1509 tessons sur un total de 1698).

\section{Fosse 37 (fig. 4)}

Le creusement principal de la fosse 37 est de forme ovoïde, une petite extension linéaire se développe sur la partie nord (Unités d'Enregistrement 101/102). Les dimensions moyennes de la structure atteignent 3,20 m de long et 2, $30 \mathrm{~m}$ de large. La fouille s'est articulée autour de deux axes de coupes nord/sud et est/ouest. En surface, un sédiment de texture limoneuse et argileuse saturé en particules de charbons de bois (us 1 et 2) laissait apparaître le sommet de quelques pierres. L'évacuation de ce limon mit progressive- ment en évidence un amas de gros blocs de pierres occupant la partie centrale de la fosse (UE 100 et 103).

Au nord-est de cette concentration de pierres, la fouille a rencontré un niveau de limon charbonneux fortement chargé en nodules de terre cuite (us 3 et 4, fig. 4, coupe E-F); à cet endroit, les parois de la fosse ne présentaient pas de trace de rubéfaction. Plusieurs formes céramiques ont été extraites de l'unité stratigraphique $n^{\circ} 3$.

Le dégagement des blocs a permis de détecter un creusement sous-jacent de forme quadrangulaire (us 6) de $80 \mathrm{~cm}^{2}$ de surface $(1 \mathrm{~m}$ de long, $80 \mathrm{~cm}$ de large et environ $10 \mathrm{~cm}$ de profondeur). Cette légère excavation recelait, comme pour le reste de la fosse 37 , os de faune et fragments de céramique. À cet endroit, la profondeur de la fosse atteint sa cote la plus basse, soit $40 \mathrm{~cm}$ sous son niveau d'apparition.

La fouille de la fosse 37 (fig. 4) s'est traduite par la collecte de 671 tessons (près de $40 \%$ de l'effectif total). La céramique a été principalement extraite de l'amas de blocs (UE 100 et 103, us 1 et 2), mais plusieurs fragments ont aussi été prélevés au sein de l'us 3 (coupe E-F). Quelques rares tessons proviennent des secteurs UE 101 et 102. Le nombre minimum d'individus (établi par le dénombrement des bords, fonds, profils développés, tessons décorés) est de 105 pièces. Cette fosse a également livré $77,8 \mathrm{~g}$ d'os de faune brûlés auxquels s'ajoutent $20 \mathrm{~g}$ de fragments de dents d'origine animale.
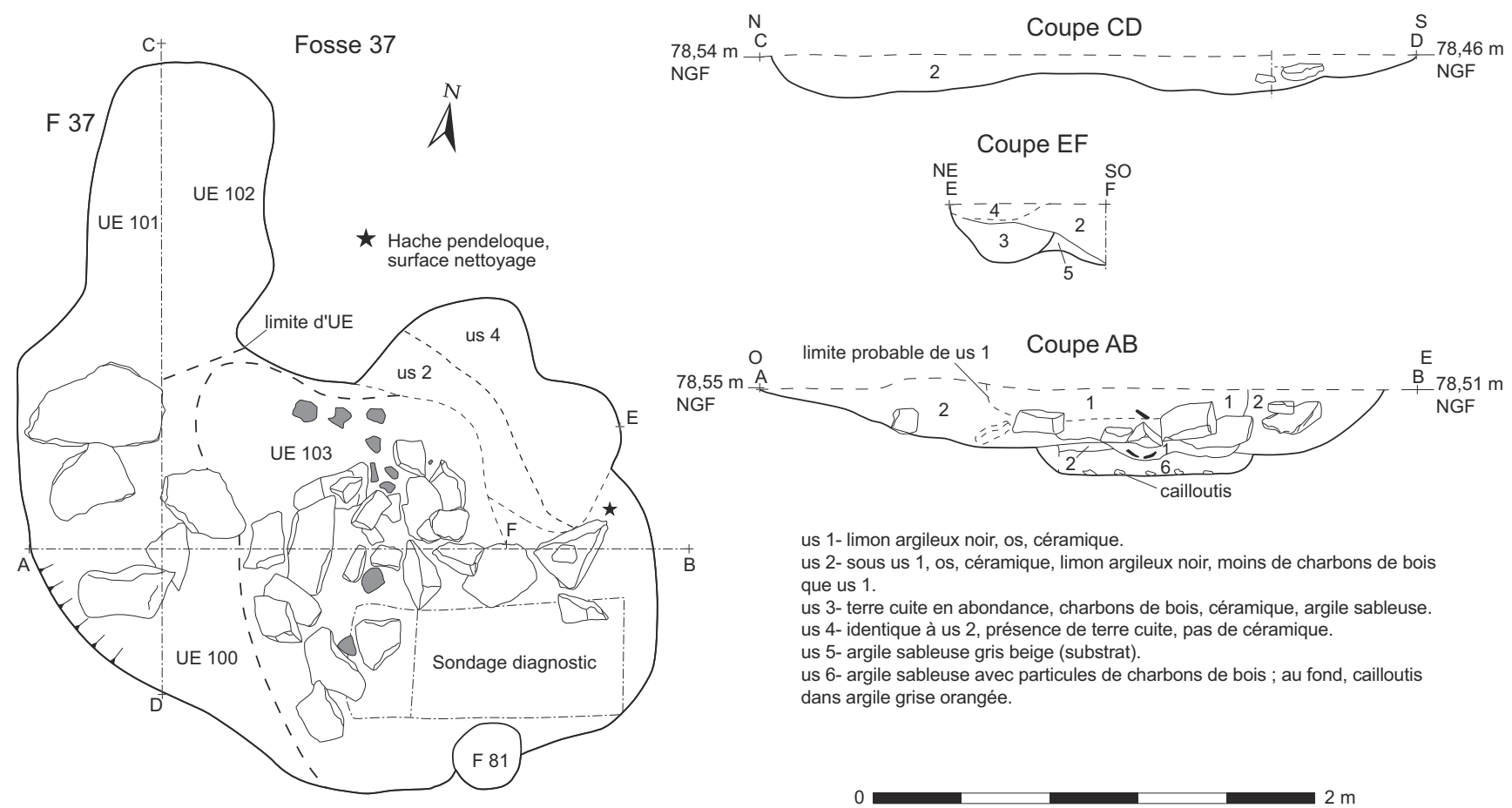

us 1 - limon argileux noir, os, céramique.

us 2 - sous us 1 , os, céramique, limon argileux noir, moins de charbons de bois que us 1.

us 3 - terre cuite en abondance, charbons de bois, céramique, argile sableuse. us 4 - identique à us 2 , présence de terre cuite, pas de céramique.

us 5 - argile sableuse gris beige (substrat).

us 6- argile sableuse avec particules de charbons de bois ; au fond, cailloutis

dans argile grise orangée.

Figure 4 : Le Petit Souper, fosse 37, plan et coupes (DAO : H. Hostein). Figure 4: Le Petit Souper, pit 37, plan and sections (DAO : H. Hostein). 


\section{Ensemble 41 (fig. 5)}

Les limites de cet ensemble se sont avérées difficiles à cerner, les différences entre le substrat et le comblement étaient assez peu marquées; de plus, des contraintes techniques ont réduit la portée de la fouille. Cette fosse a été observé sur $5 \mathrm{~m}$ de long et 4,50 m de large; sa profondeur atteint, tout au plus, $15 \mathrm{~cm}$. Le fond est relativement plat. Le comblement principal (us 2) est un sable argileux de teinte grise orangée, montrant peu de différence avec le substrat; quelques tessons et charbons de bois ont été récoltés dans cette couche. Plusieurs creusements annexes entament ce niveau de sable
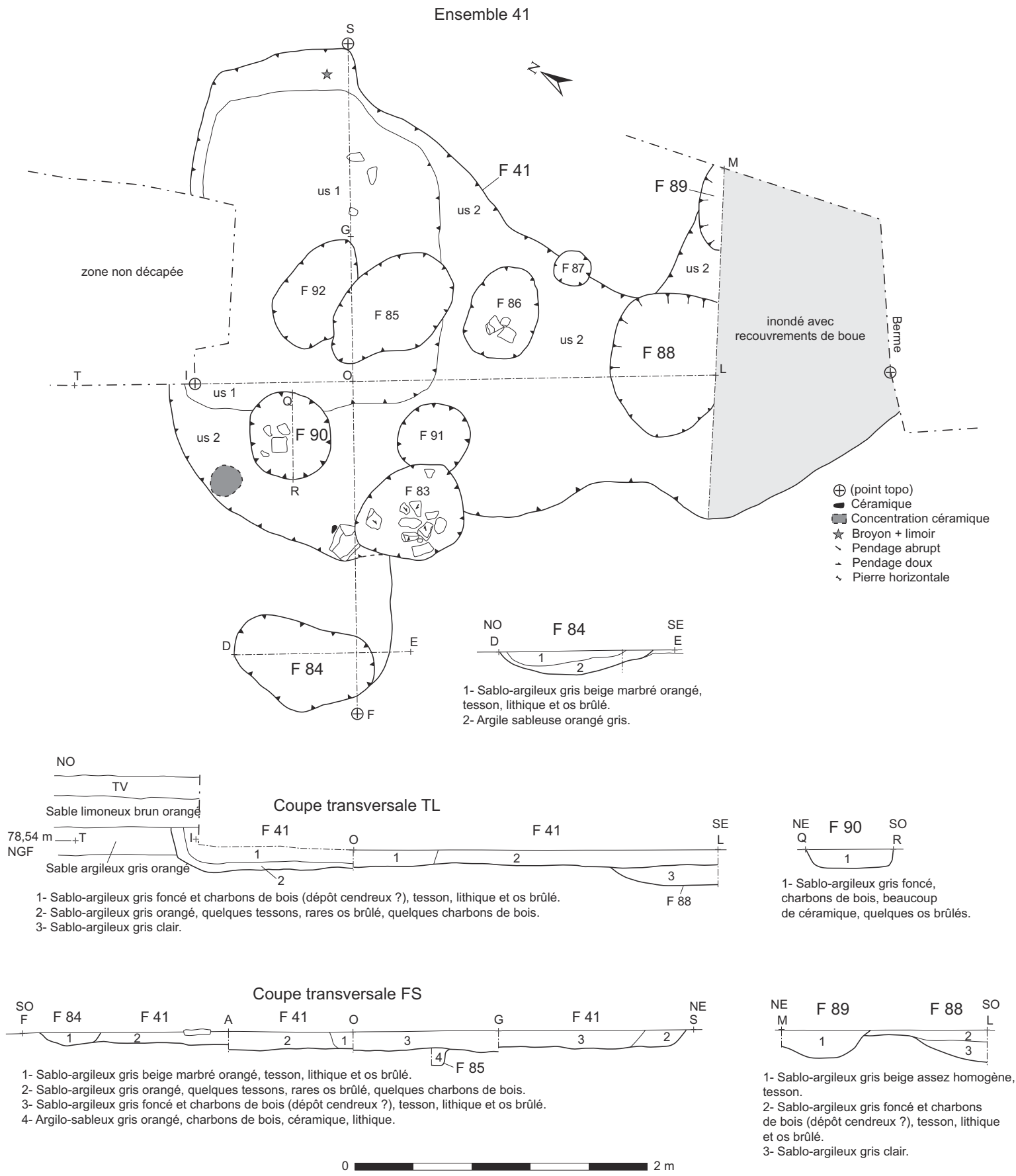

Figure 5 : Le Petit Souper, ensemble 41, plan et coupes (DAO : H. Hostein). Figure 5: Le Petit Souper, ensemble 41, plan and sections (DAO : H. Hostein). 
argileux. Le plus vaste d'entre eux (us 1) prend une forme quadrangulaire; il est comblé par un sable gris contenant de nombreuses particules de charbons de bois associées à des restes osseux humains brûlés, lithiques et céramiques. D'autres creusements secondaires, de taille plus réduite, ont été repérés. Parmi eux, les creusements 84,88 et 90 qui ont livré des fragments d'os humains fortement brûlés associés à des pièces lithiques et des tessons de céramiques. La présence ponctuelle de petits blocs de grès dans cet ensemble peut être relevée; l'interprétation de ces concentrations de blocs comme éléments de calage semble fonder l'hypothèse d'un fond de cabane. Toutefois, les conclusions de l'étude anthropologique font état de la présence dans F 41 (us 1 et us 2), F 84, 88 et 90 de restes humains très brûlés présents en faibles quantités (24 grammes); de fait, la question d'un aménagement à creusements multiples dédié, au moins en partie, à des dépôts volontaires de restes humains, est posée.

La fosse F 41 et les creusements associés (F 84, 88 et 90 notamment) ont présenté, au terme de leur fouille, un lot de 339 tessons ( 258 pour $\mathrm{F} 41,80$ pour $\mathrm{F} 90,1$ bord pour F 88). Le NMI s'élève à 32 pour F 41 (us 1 et us 2), et 8 pour F 90.

\section{Fosse 43 (fig. 6)}
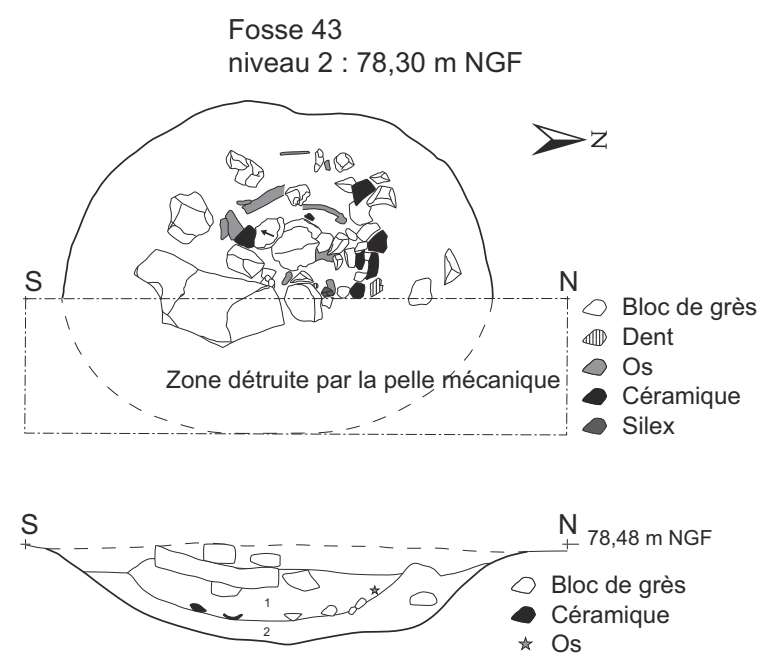

1- Sédiment sablo-argileux gris quasi homogène (racines) renfermant de nombreux blocs de grès, céramique, terre cuite et os.

2- Sédiment argilo-sableux gris clair à orangé beige, homogène, rares blocs de grès.

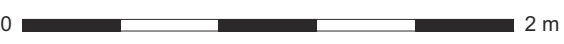

Figure 6: Le Petit Souper, fosse 43, plan et coupe (DAO : H. Hostein).

Figure 6: Le Petit Souper, pit 43, plan and section (DAO : H. Hostein).
Le plan de la fosse semble adopter une forme ovalaire. Le creusement atteint une profondeur de $40 \mathrm{~cm}$ sous le niveau d'apparition. Le comblement est constitué par un sédiment de texture sableuse et argileuse contenant de nombreux blocs de grès. La céramique provient de ce niveau; le NMI s'élève à 34 vases. La fouille a mis en évidence la présence d'os longs de faune parmi les blocs de pierres, soit $389 \mathrm{~g}$ d'os et $31 \mathrm{~g}$ de dents. Réduits à l'état spongieux, ces ossements n'ont pu être précisément identifiés; par ailleurs, leur texture indique qu'ils n'ont pas été exposés à de fortes températures ni même soumis à la flamme d'un foyer. Des pièces de silex et quelques charbons de bois complètent l'inventaire du mobilier recueilli dans cette fosse. La fonction de fossedépotoir a été proposée pour cette structure.

207 tessons ont été retirés de cette fosse située au nord de F 41 ; mais, cela ne constitue qu'une partie de son corpus. En effet, lors de la phase de décapage réalisée dans des conditions météorologiques particulièrement défavorables, une des chenilles de la pelle mécanique a détruit une partie de cette structure qui était alors recouverte de plusieurs centimètres de boue liquide.

\section{Fosses 67 et 68 (fig. 7)}

Les fosses 67 et 68 ont été découvertes un peu à l'extérieur du périmètre d'étude défini par la prescription de fouille. La fosse 67 présente un plan circulaire de $1 \mathrm{~m} 60$ de diamètre et $60 \mathrm{~cm}$ de profondeur. Un sédiment sablo-argileux de teinte grisâtre à brune comble la fosse. De nombreux blocs de grès, disposés sans organisation particulière, y ont été découverts. Cette fosse a livré 170 fragments de poteries pour un NMI de 22 vases. La présence de fragments de pesons atteste d'une activité artisanale liée au tissage; ces éléments de terre cuite étaient associés à des morceaux de parois de four. À proximité immédiate de la fosse 67, la structure 68 n'a pas été vue dans sa totalité. Sa profondeur ne dépasse pas $20 \mathrm{~cm}$, elle a livré 31 tessons. Le NMI de vases est modeste (5 individus).

La description du comblement de F 67 s'applique également à $\mathrm{F} 68$, cette similitude semble induire une proximité fonctionnelle et chronologique entre ces deux fosses. On peut remarquer qu'aucun reste osseux n’a été récolté.

\section{Fosse 62 (fig. 8)}

Au centre du décapage, la fosse 62 s'inscrit dans un ensemble qui associe les structures 114 à 116. Sa stratigraphie, se développant sur une vingtaine de centimètres, est plus complexe que celles des structures précédemment décrites; en effet, onze couches de comblement ont été identifiées. Dans l'ensemble, le sédiment de F 62 se distingue 

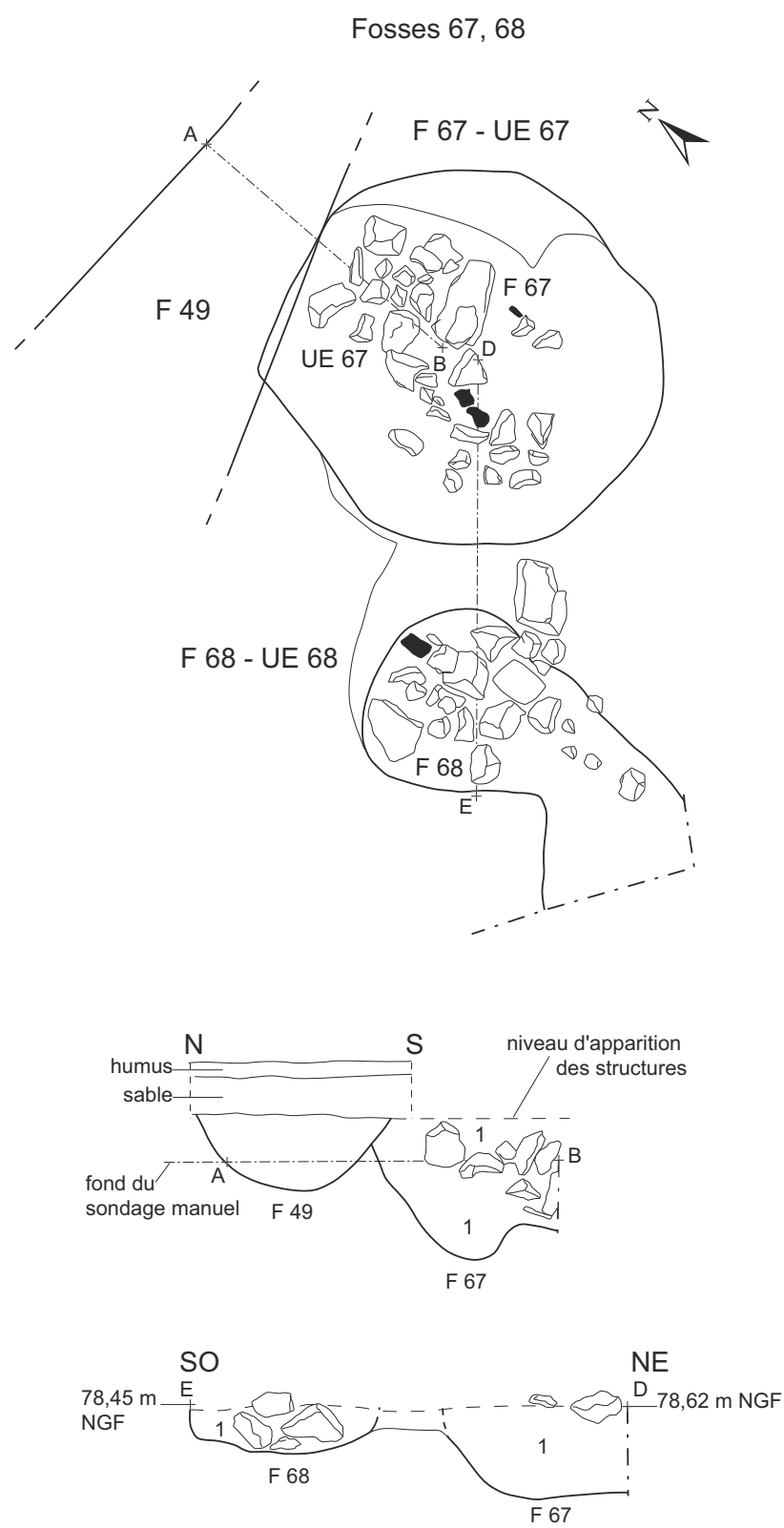

1- Argile sableuse grise tachetée de brun, assez compacte, nombreux blocs de grès, charbons et céramique.

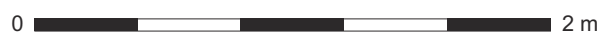

Figure 7 : Le Petit Souper, fosses 67 et 68, plan et coupes (DAO : H. Hostein).

Figure 7: Le Petit Souper, pits 67 et 68, plan and sections (DAO : H. Hostein).

par une forte teneur en charbons de bois. 91 tessons ont été recueillis dans cette fosse, essentiellement dans l'us 9; le NMI s'élève à 12 vases. Une faible quantité de tessons (13 fragments) a, par ailleurs, été recueillie dans les faits 114 à 116.

\section{Autres structures}

La description des fosses principales doit être complétée par un bref exposé concernant les autres structures. Concernant les axes fossoyés, le fossé 74 a livré quelques tessons de facture protohistorique ainsi qu'une dizaine de grammes de scories; toutefois, la relation de ce fossé avec l'occupation du Bronze final n'a pas été établie. Quant à l'axe de cheminement (F 25/48/49), aucun élément matériel ne permet d'avancer une chronologie; la fouille a néanmoins établi que cet axe recoupe le fossé 74 . Il recoupe également la fosse 67 qui est attribuée au Bronze final II b/III a.

Enfin, l'ensemble F 38 et ses multiples creusements présente des dimensions importantes $(4,60 \mathrm{~m}$ de long pour 3,40 m de large) mais, paradoxalement, il s'est avéré très pauvre en mobilier (24 tessons; NMI : 3). L'hypothèse d'un fond de cabane arasé a été formulée pour l'identification de cette structure.

\section{Présentation du Mobilier par conteXte}

L'ensemble des fragments de céramique se rapportant à l'occupation de l'étape moyenne du Bronze final regroupe 1698 tessons; le NMI global s'élève à 245 vases. Le calcul du NMI a été réalisé par comptage des fragments de bords, de fonds, de tessons décorés et des profils suffisamment développés pour être individualisés.

Le détail de ce travail de quantification est présenté dans le tableau de synthèse $n^{\circ} 1$.

\section{Fosse 37}

\section{Description technique}

Trois groupes de pâtes ont été définis (pâtes fine, semifine, grossière façonnée).

Le groupe des pâtes fines (groupe 1) prend en compte les vases pour lesquels le dégraissant n'est pas ou peu visible. Les traces de montages sont très discrètes, les surfaces particulièrement soignées. On trouve essentiellement dans ce groupe les écuelles et assiettes tronconiques.

Le groupe des pâtes semi-fines (groupe 2) prend en compte des productions de qualité pour lesquelles le dégraissant est visible, parfois abondant mais finement calibré. Cela concerne les mêmes types de vases que ceux du premier groupe.

Enfin, le troisième groupe propose une définition correspondant à l'expression générique "pâte grossière ". Le critère discriminant réside ici dans le traitement des surfaces : des traces digitées linéaires, liées au façonnage de la pâte, marquent les faces externes et/ou internes. Ces traces peu- 

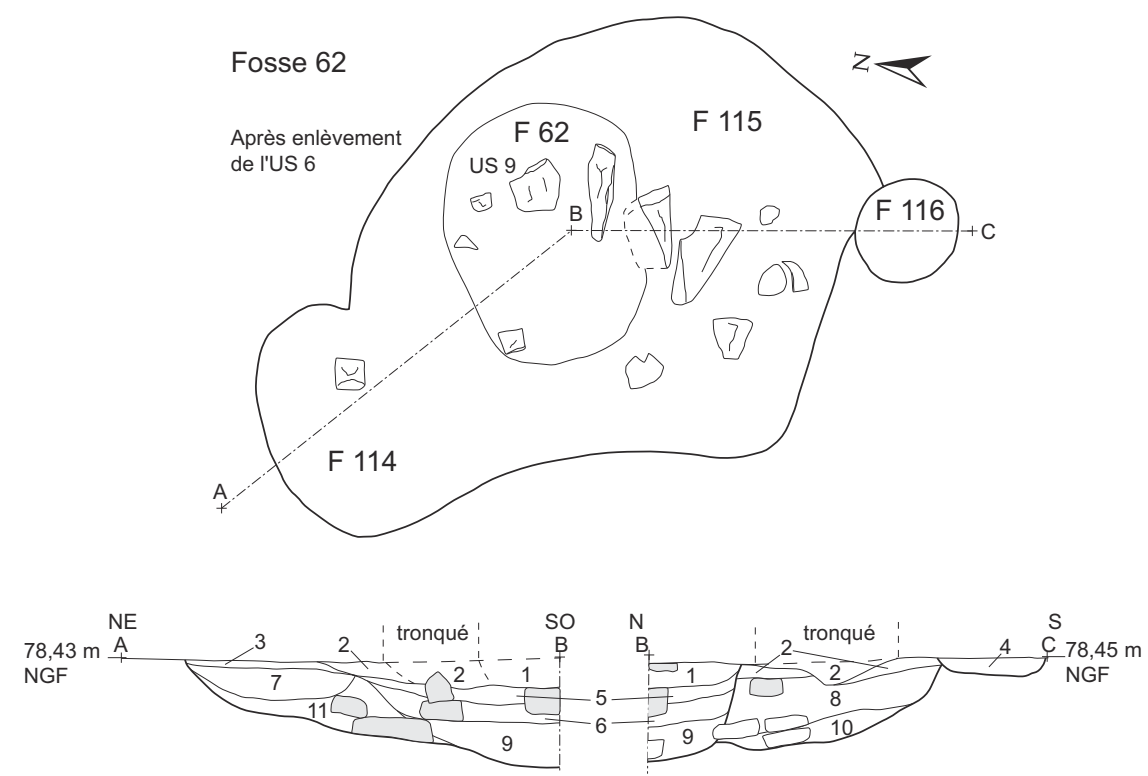

Figure 8 : Le Petit Souper, fosse 62, plan et coupe (DAO : H. Hostein).

Figure 8: Le Petit Souper, pit 62, plan and section (DAO : H. Hostein).
F 62:

1- Sable argileux gris foncé, nombreux charbons de bois.

2- Sable argileux gris marron renfermant de nombreux blocs de grès. F 114 :

3- Sable argileux marron gris homogène.

F 116:

4- Sable argileux verdâtre à orangé (= TP 116). F 62:

6- Sable limoneux gris brun homogène, céramique. 5- Sable argileux gris homogène.

F 114 :

7- Sable argileux beige, homogène.
F 115 :

8- Idem us 7.

F 62:

9- Sable limoneux gris foncé, riche en charbons de bois, os (brûlé) et céramique.

F 115:

10- Sable argileux beige orangé

11- Idem us 10.

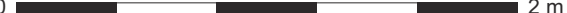

\begin{tabular}{|c|c|c|}
\hline $\begin{array}{c}\text { numéro } \\
\text { de structure }\end{array}$ & $\begin{array}{c}\text { nombre } \\
\text { de tessons }\end{array}$ & $\begin{array}{c}\text { nombre } \\
\text { minimum d'individus }\end{array}$ \\
\hline 14 & 13 & 2 \\
\hline 27 & 70 & 5 \\
\hline 37 & 671 & 78 \\
\hline 38 & 24 & 3 \\
\hline 39 & 45 & 5 \\
\hline 40 & 5 & 1 \\
\hline 41 & 258 & 32 \\
\hline 42 & 21 & 5 \\
\hline 43 & 207 & 34 \\
\hline 62 & 91 & 12 \\
\hline 67 & 170 & 22 \\
\hline 68 & 31 & 5 \\
\hline 80 & 1 & 1 \\
\hline 88 & 1 & 1 \\
\hline 90 & 80 & 8 \\
\hline 115 & 5 & 2 \\
\hline
\end{tabular}

vent être continues, obliques ou verticales, voire ponctuelles (extrémité des doigts). Ce traitement peut, dans certains cas (applications couvrantes) être assimilé à un décor.

La proportion par groupes s'établit ainsi : pâte grossière 60 , $5 \%$ de l'effectif total; pâte semi- fine $21 \%$; pâte fine $18,4 \%$.

\section{Pâtes fines et semi-fines: formes et décors (fig. 9, 10, 11, 12)}

Les assiettes à profil tronconique dominent l'effectif de la production en pâte fine ou semi-fine (15 exemplaires). À l'exception d'un vase (fig. $9: \mathrm{n}^{\circ} 1$ ), elles présentent toutes un profil simple, dépourvu de segmentation. L'absence de décor interne, fréquent sur ce type de récipient, peut être relevée.

Cinq types de pâte ont été utilisés dans la conception de ces vases. Pour le récipient (fig. 9) $n^{\circ} 1$, la pâte est de teinte jaune/beige, les parois présentent ponctuellement des traces

Tableau 1 : Le Petit Souper, nombre de restes (NR) et nombre minimum d'individus par structure (NMI)

Table 1 : Le Petit Souper, many rests (N.R.) and minimum number individuals by features. 
us 1 et 2
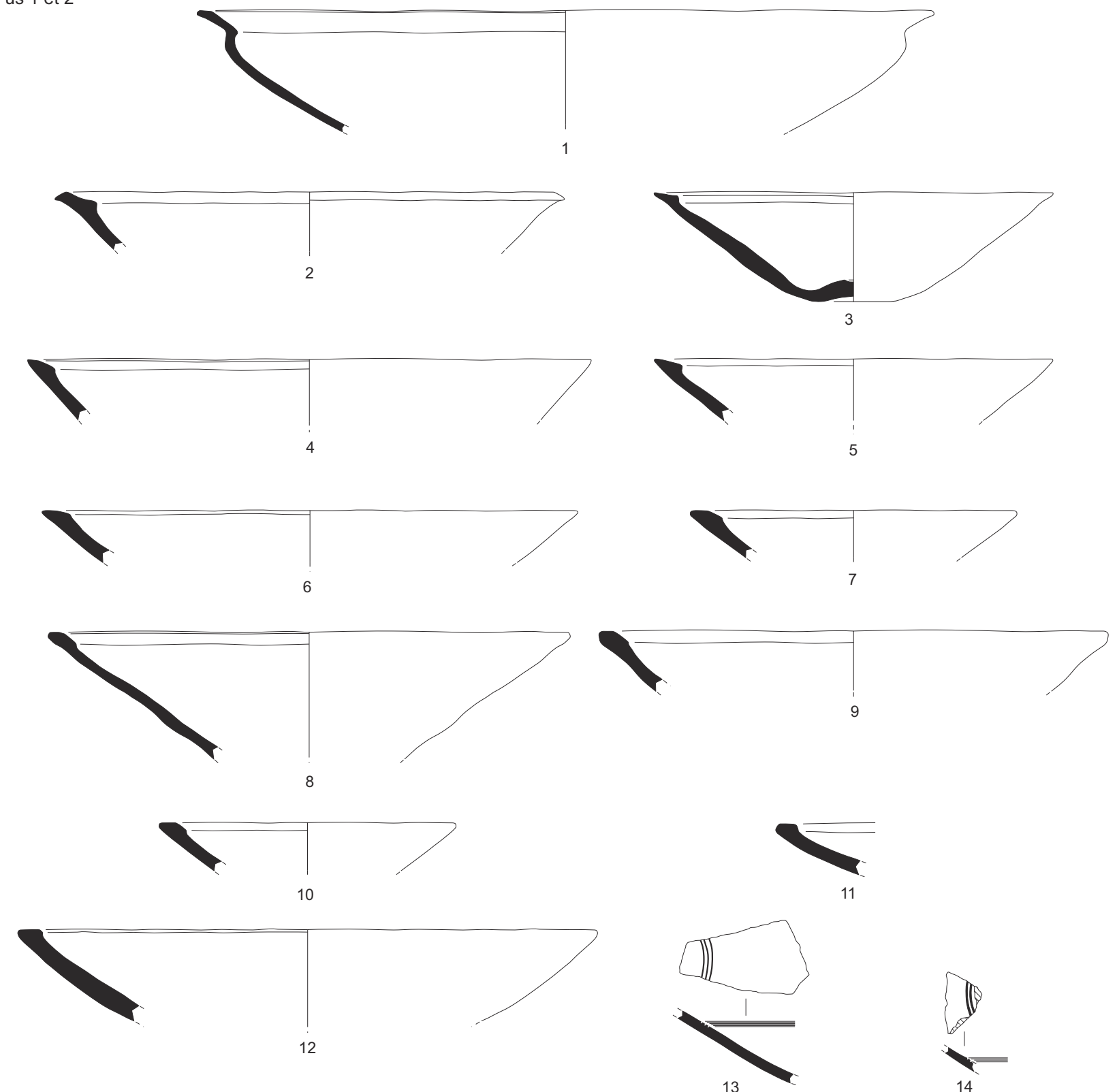

us 3
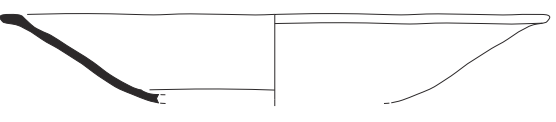

15
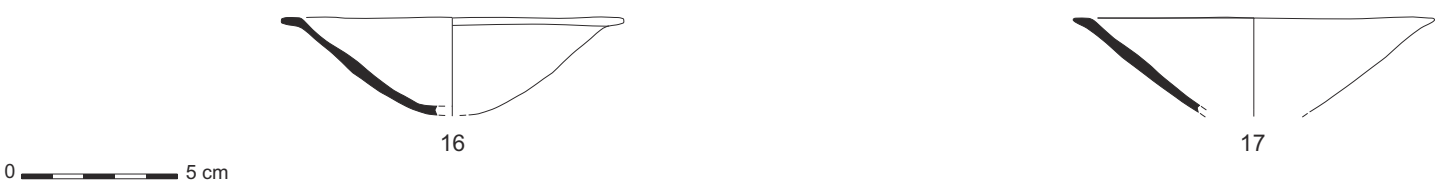


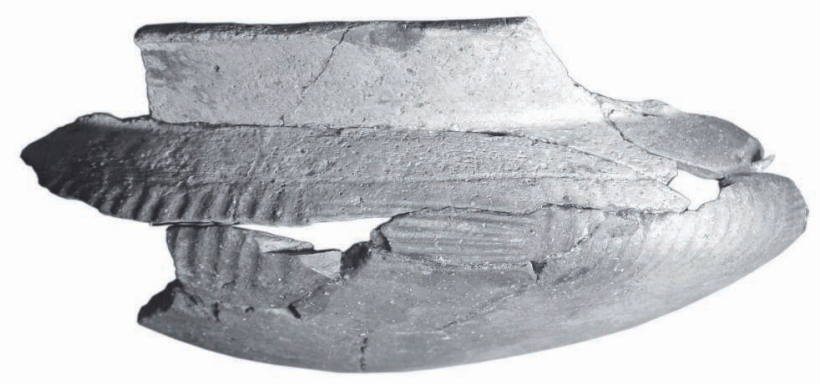

Figure 10 (photo) : Le Petit Souper, fosse 37, vase $\mathrm{n}^{\circ} 1$, fig. 11. Figure 10 (photo): Le Petit Souper, pit 37, ceramic $n^{\circ} 1$, fig. 11.

Figure 11 (dessin) : Le Petit Souper, fosse 37, fine écuelles (DAO : H. Hostein).

Figure 11 (dessin): Le Petit Souper, pit 37, fine bowls (DAO: H. Hostein).

us 1 et 2
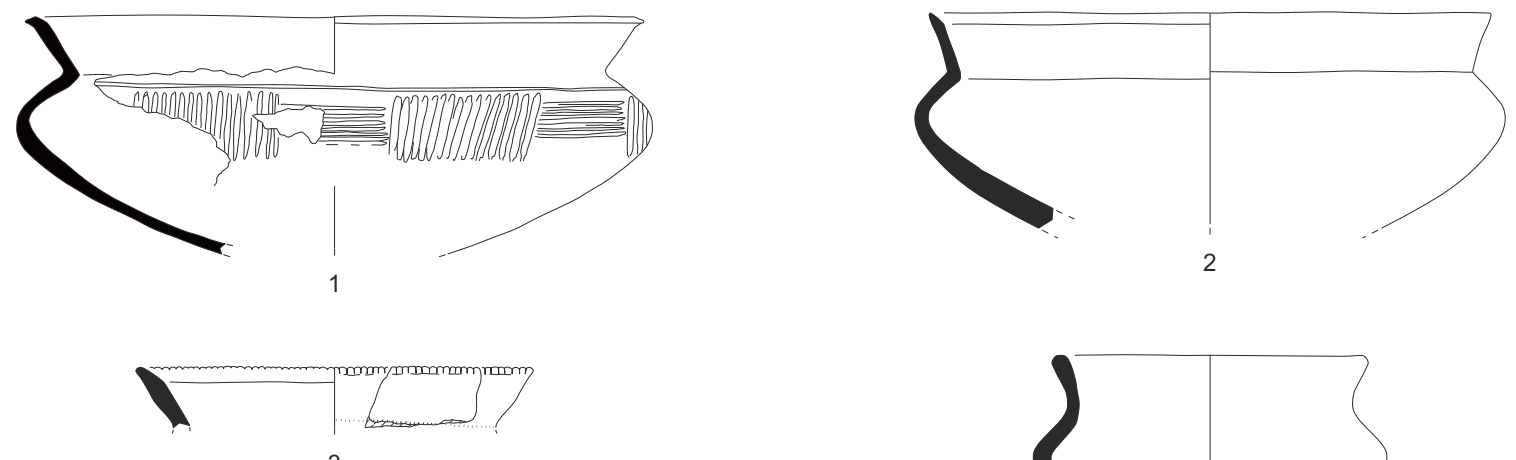

3
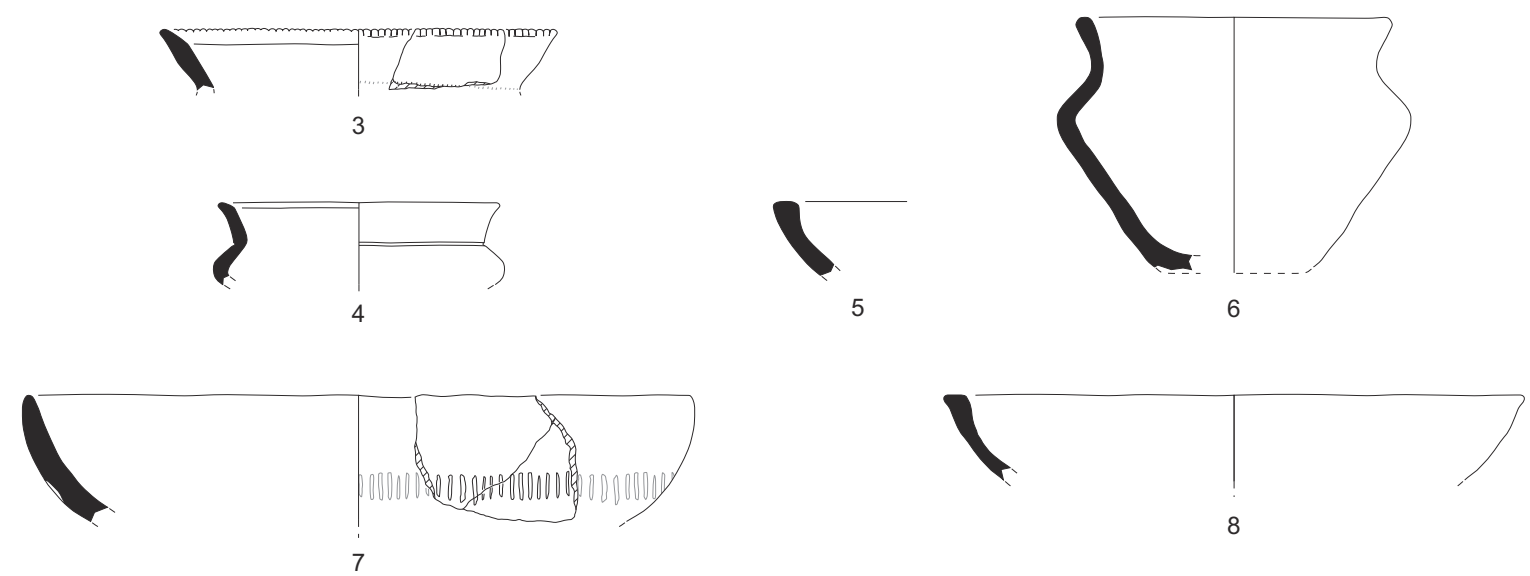

8

us 3
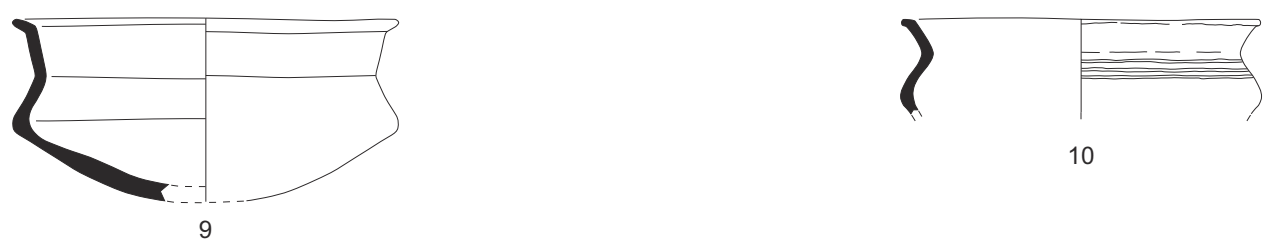

10
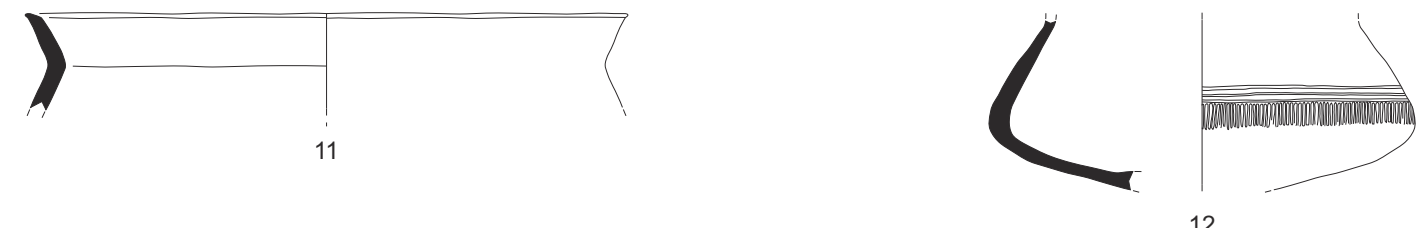

$0-5 \mathrm{~cm}$ 
us 1 et 2
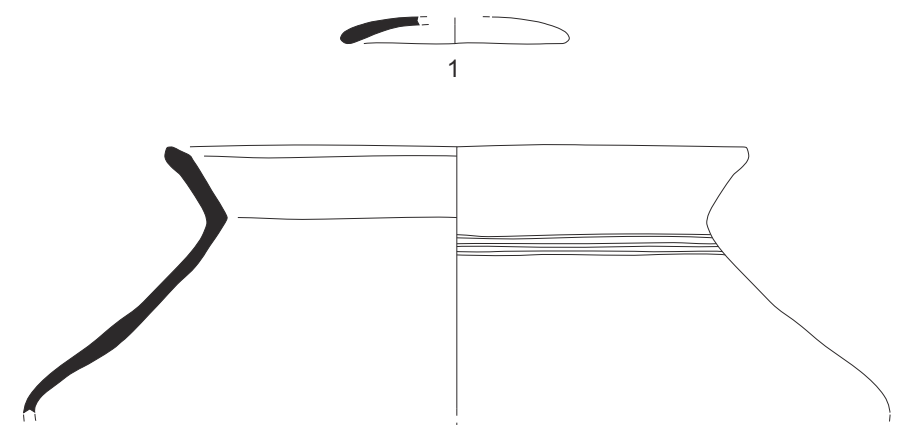

2
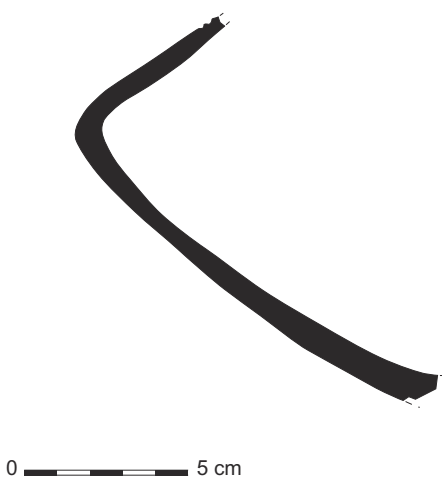

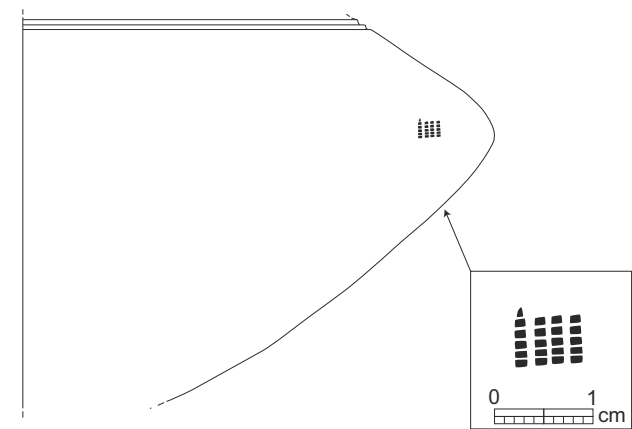

3

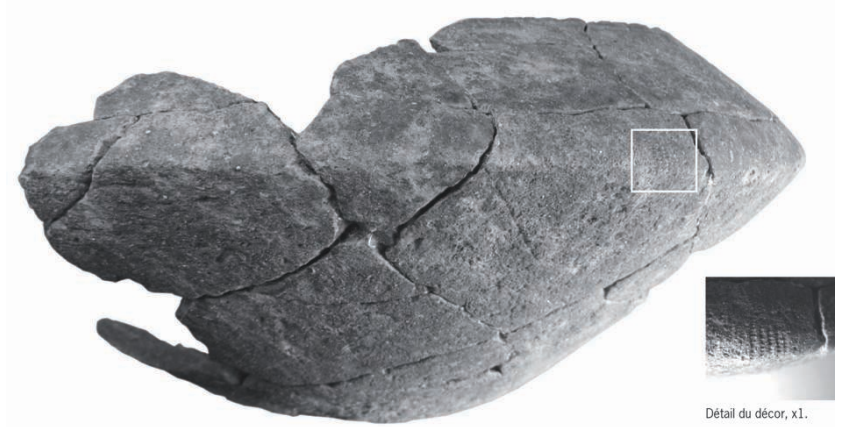

Figure 13 : Le Petit Souper, fosse 37, vase n 3, fig. 12. Figure 13: Le Petit Souper, pit 37, ceramic n 3, fig. 12.

noirâtres, probablement liées à des coups de chauffe lors de la cuisson. Un second type (majoritaire) présente une teinte gris foncé au cœur; les surfaces sont recouvertes d'un revêtement noir, lissé et légèrement micacé. Pour les vases concernés, la cuisson est de bonne qualité (fig. $9: \mathrm{n}^{\circ}$ 4, 6, 7, $8,9,10)$. Une variante de teinte gris claire concerne notamment les assiettes de petits formats (fig. $9: \mathrm{n}^{\circ} 15,16$ et 17), les surfaces de ces récipients sont altérées.

Enfin, les assiettes (fig. 9) nº 11 et 12 sont réalisées à partir d'une argile de texture sableuse.
Figure 12 : Le Petit Souper, fosse 37, céramique fine et semi-fine (DAO : H. Hostein).

Figure 12: Le Petit Souper, pit 37, fine and semifine ceramics (DAO: $H$. Hostein).
Cet inventaire des groupes techniques traduit la variété des productions rencontrées, sans qu'il soit possible de distinguer les productions locales des apports exogènes.

Sept vases présentent un diamètre inférieur ou égal à $21 \mathrm{~cm}$. La lèvre peut être facettée (fig. $9: \mathrm{n}^{\circ} 4,7,8,9$, 10), oblique (fig. $9: \mathrm{n}^{\circ} 1$ ), amincie avec un décrochement interne bien marqué (fig. $9: \mathrm{n}^{\circ} 3,5$ ) ou sans décrochement (fig. $9: n^{\circ} 6$ ), en méplat horizontal (fig. $9: n^{\circ} 11,12$ ), à gorge interne et ressaut externe (fig. $9: n^{\circ} 2$ ). On remarque pour les petits formats (fig. $9: \mathrm{n}^{\circ} 15,16,17$ ) la rupture du profil bord/paroi : le bord est largement étiré vers l'extérieur. Les fonds ne sont pas conservés, à l'exception de l'exemplaire ombiliqué de l'assiette (fig. 9) n 3 . Les décors sont absents de cette série; toutefois, deux exemples, très partiels, de décors en guirlande réalisés au peigne ont été décelés sur les faces internes altérées de deux fragments d'assiettes (fig. 9 : $\mathrm{n}^{\circ} 13$ et 14$)$.

Les écuelles à bord oblique sont moins nombreuses (une dizaine d'exemplaires en prenant en compte les bords attribuables à cette catégorie). Ces vases se distinguent par une paroi à carène souple, arrondie précédant un épaulement marqué. L'absence de fond n'a pas permis de détecter la présence de coupe à pied creux dans cet assemblage. L'écuelle (fig. 11) $\mathrm{n}^{\circ} 1$ présente un décor en panneaux alternés de cannelures horizontales et verticales, légèrement obliques. Ce décor se 
développe sur l'épaulement. Une cannelure horizontale limite son développement dans la partie haute. Le bord de ce vase est marqué par un petit décrochement externe.

Le décor au peigne à trois dents est attesté sur une écuelle (fig. $11: \mathrm{n}^{\circ} 10$ ).

On peut remarquer une écuelle de petit format issue de la fosse 37 (fig. $11: n^{\circ} 4$ ), une cannelure souligne la jonction bord/épaulement.

Le vase (fig. 11) $\mathrm{n}^{\circ} 12$ caractérisé par un profil surbaissé, un épaulement très développé et un resserrement des parois à la base du col, est l'unique représentant de ce type de profil dans l'assemblage de F 37. Le registre décoratif, appliqué sur la partie basse de son épaulement, associe un décor en ruban de fines cannelures verticales très resserrées à trois fines cannelures horizontales.

La typologie décorative est également illustrée par un bord (fig. $11: \mathrm{n}^{\circ} 3$ ) décoré de fines incisions sur l'extrémité de sa lèvre; une autre série d'incisions ou d'impressions (décor incomplet) orne la jonction col/panse.

Un seul gobelet à épaulement de type large (fig. 11 : $n^{\circ}$ 9) a été découvert dans la fosse 37. Cela permet de souligner l'extrême rareté, voire l'absence, dans le corpus du Petit Souper, du gobelet à épaulement de style RSFO dans son expression classique : carène marquée et haut col cylindrique. Le gobelet du Petit Souper est marqué par un col cylindrique assez court légèrement ouvert. Une fine cannelure souligne la jonction épaule/encolure. Le fond est plat.

La série de la fosse 37 présente un vase de forme relativement atypique (fig. $11: \mathrm{n}^{\circ}$ 6). Ce petit récipient (à peine $9 \mathrm{~cm}$ de haut) adopte un profil segmenté habituellement réservé aux vases de plus grandes dimensions.

Les fragments de bords droits des formes tronconiques (fig. 11) $n^{\circ} 5$ et 8 présentent une nette rupture du profil dans leur partie haute. Les bords sont bien individualisés et ne s'inscrivent pas dans la continuité de la paroi. Cela constitue une différence avec les vases de même modèle présentés plus haut (fig. $9: \mathrm{n}^{\circ} 11$ et 12 ). La restitution graphique n'a pu être effectuée pour le bord $n^{\circ} 5$, mais l'orientation de son profil permet d'y voir un vase assez profond. Dans ce cas précis, le bord $\mathrm{n}^{\circ} 5$ correspond à la définition que l'on confère aux jattes tronconiques à bord vertical. Apparenté aux vases précédents, le bord à parois convexes (fig. 11) n 7 semble de facture plus archaïque; cela tient à la texture très sableuse de la pâte, à la simplicité de son discret décor cannelé et à sa lèvre amincie.

Deux fragments de jarres à panse biconique représentent cette catégorie de vase (fig. $12: n^{\circ} 2$ et 3). Pour ces deux récipients, un décor de cannelures au peigne à trois dents est appliqué sur la partie haute de l'épaule, à proximité de la jonction épaule/bord. Sur la ligne de carène de la jarre $\mathrm{n}^{\circ} 3$ figure un timbre estampé de petite taille $(10 \mathrm{~mm}$ par
$6 \mathrm{~mm}$ ), de forme quadrangulaire et constitué par quatre lignes verticales de petites impressions de la taille d'une tête d'épingle. L'usage d'une matrice est vraisemblable. La fonction ornementale de ce motif est peu probable au regard de sa discrétion et de son isolement et ce, d'autant moins que les dimensions du fragment sont suffisamment importantes pour voir que cette empreinte n'est pas reproduite sur une autre partie de la paroi.

Enfin, il faut mentionner un fragment de couvercle (fig. $12: \mathrm{n}^{\circ} 1$ ) de $10 \mathrm{~cm}$ de diamètre.

\section{Pâtes grossières : formes et décors (fig. 14, 15, 16, 17)}

La tendance au profil biconique s'affirme nettement dans cette série. La segmentation de la paroi est généralement prononcée, l'épaulement peut être particulièrement développé (fig. $14: \mathrm{n}^{\circ} 1$ et 3 ). Les formes dotées d'un bord complexe (fig. $14: n^{\circ} 1,2,3,5$ ) côtoient ceux pour lesquels le col est atrophié (fig. $14: n^{\circ} 4,6$ ).

La thématique ornementale est dominée par le décor d'impressions sur la ligne de carène, treize vases en sont pourvus (fig. $14: \mathrm{n}^{\circ} 1,2,3,4,5,6$; fig. $15: \mathrm{n}^{\circ} 4,5,6,7,8$, $10,12)$. Dans la plupart des cas, il s'agit d'une simple ligne de digitations; ce décor peut aussi être décliné en double rangée de digitations (fig. $14: n^{\circ} 3$; fig. $15: n^{\circ} 5$ ). Le vase (fig. 14) $n^{\circ} 5$ propose, avec son décor d'ocelles, une variante à ce principe décoratif.

L'usage du cordon appliqué digité est ici médiocrement exprimé, les exemples relevés (fig. $14: \mathrm{n}^{\circ} 6$; fig. $15: \mathrm{n}^{\circ} 6,7$, 8) sont mal façonnés et écrasés contre la paroi; deux tessons présentent des segments de cordon lisse appliqué (fig. 15 : $\mathrm{n}^{\circ} 9$ et 11$)$.

Quelques bords sont ornés de digitations (fig. $14: \mathrm{n}^{\circ} 4$; fig. $\left.15: \mathrm{n}^{\circ} 1,2,3\right)$ systématiquement implantées sur l'extérieur de la lèvre.

Par ailleurs, certains vases présentent sur leur face externe des traces digitées couvrantes situées sous la carène; elles peuvent être continues ou ponctuelles et resserrées (fig. 14 : $\mathrm{n}^{\circ} 1$ et 2 ; fig. $15: \mathrm{n}^{\circ} 10,11,12$ et 13). Liées au modelage de la pâte, ces empreintes revêtent également un caractère ornemental (fig. $15: n^{\circ} 10$ et 13 ).

Le registre des éléments de préhension est illustré par une petite languette recourbée (fig. $15: \mathrm{n}^{\circ} 14$ ).

\section{Comparaisons et attribution chronologique}

L'assemblage céramique de la fosse 37 réunit des formes et décors caractéristiques de la phase moyenne du Bronze final.

Plus précisément, certains éléments trouvent référence dans des contextes de la fin de la phase ancienne ou du début de la phase moyenne du Bronze final.

C'est notamment le cas de l'écuelle à bord oblique (fig. 11) $\mathrm{n}^{\circ} 1$ ornée d'un décor cannelé en panneaux. Ce type de 
us 1 et 2
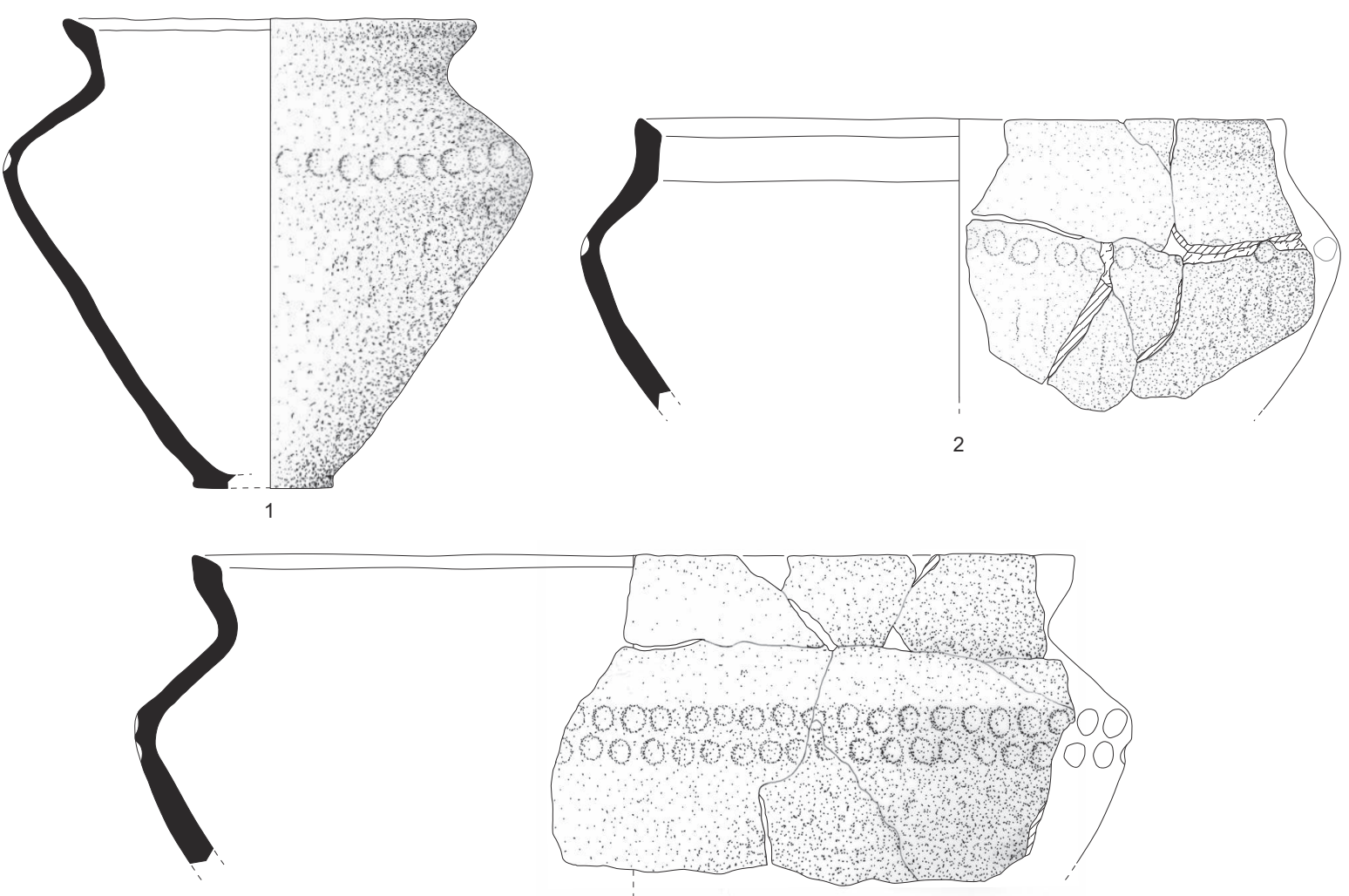

3
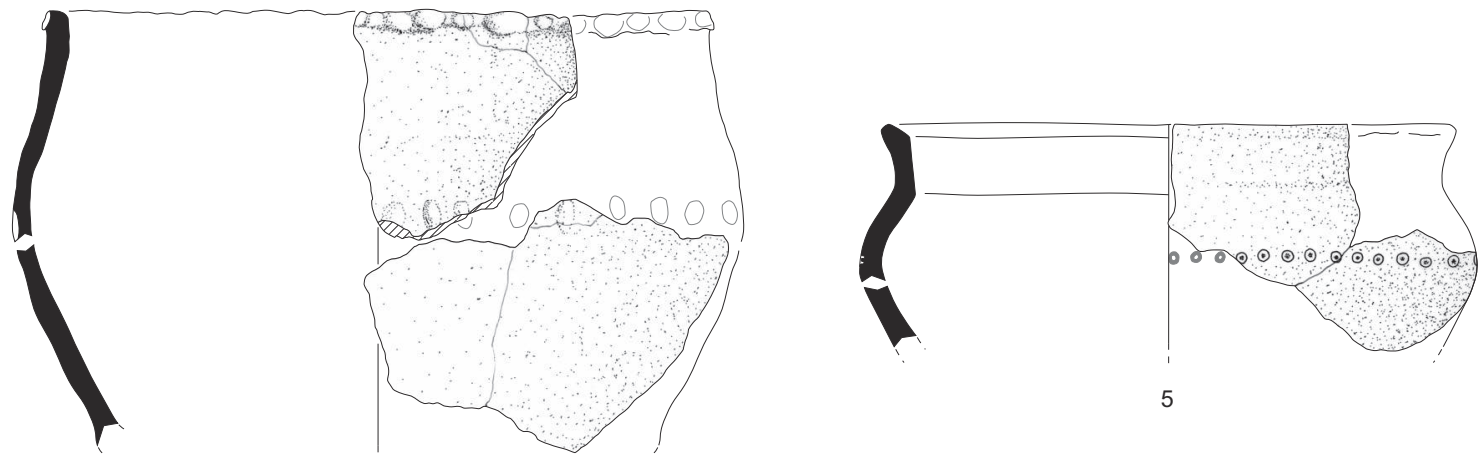

5

4

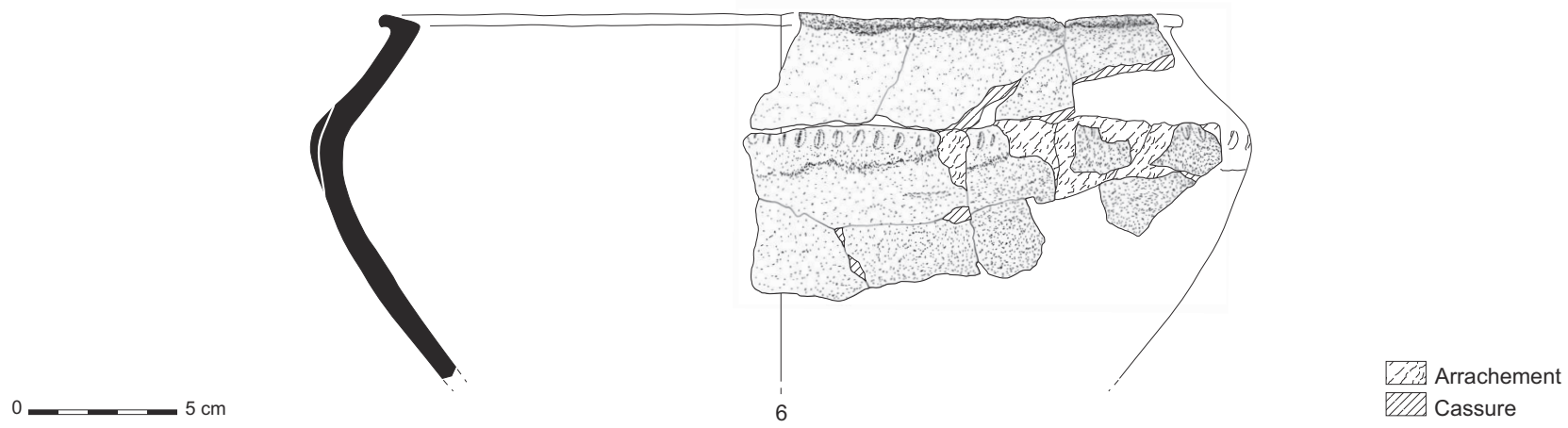

Figure 14 : Le Petit Souper, fosse 37, céramique grossière (DAO : H. Hostein). Figure 14: Le Petit Souper, pit 37, coarse ceramics (DAO: H. Hostein). 
us 1 et 2

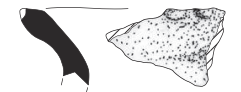

1

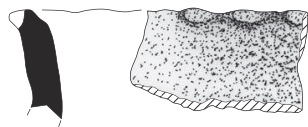

2

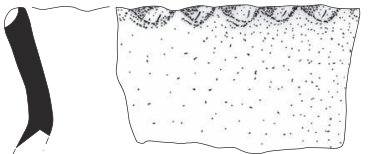

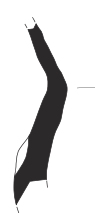

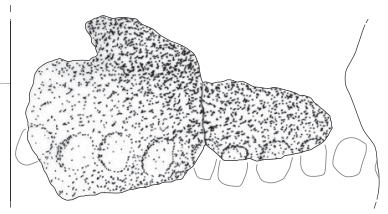

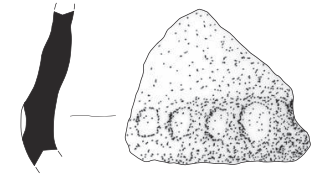

6

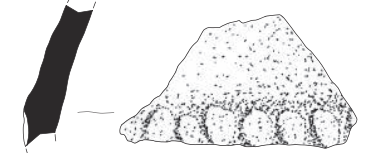

7
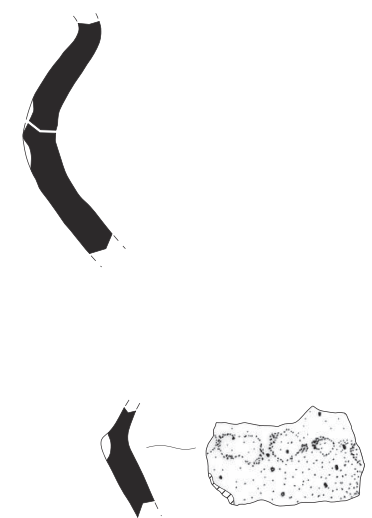

8

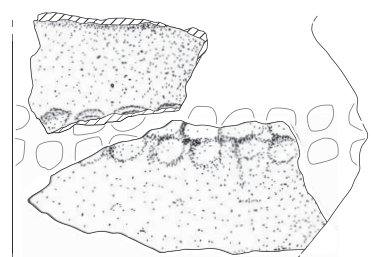

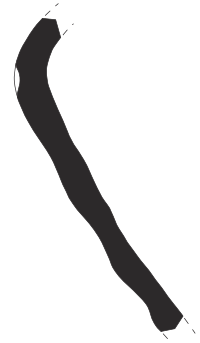
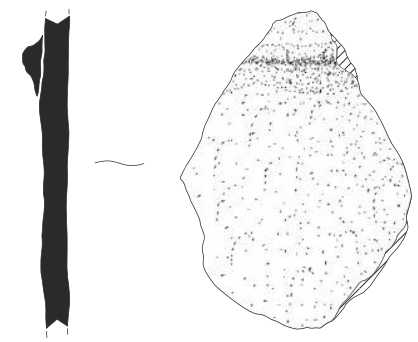

11
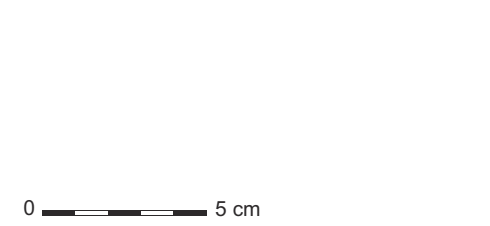
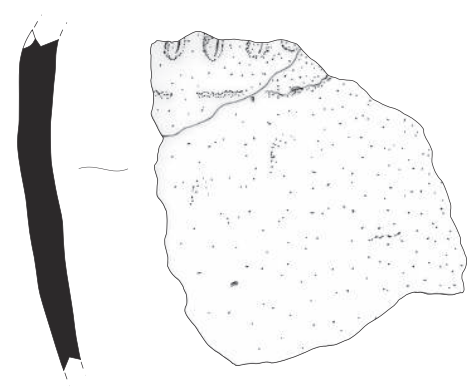

12

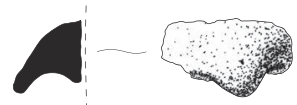

14

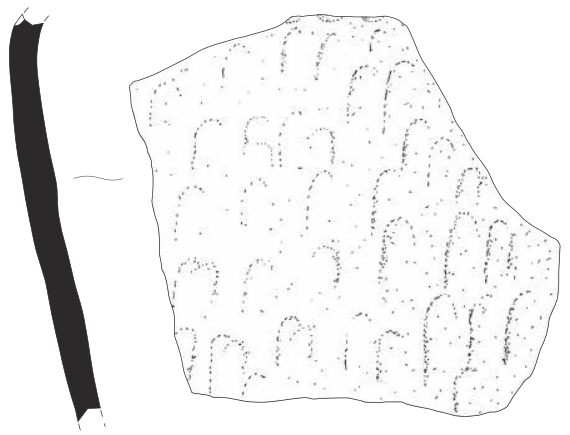

13

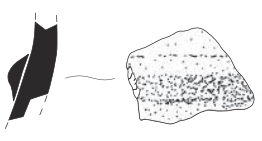

9

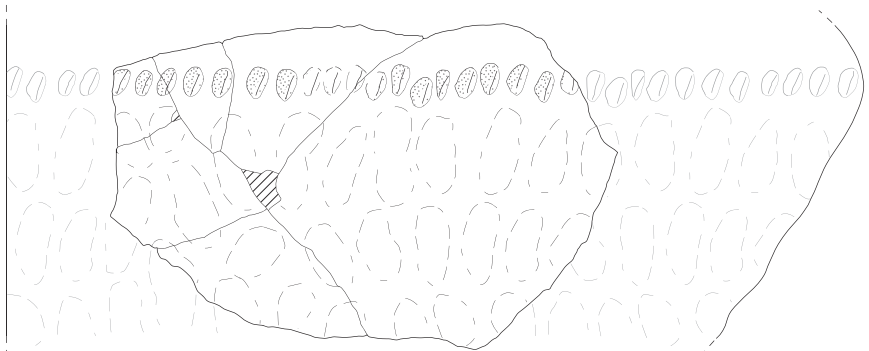

10 
décor, alternance de cannelures verticales et horizontales, est répertorié dans le corpus de Rancogne en Charente sur des écuelles datées de la fin du Bronze final II a ou du début du Bronze final II b (Gruet, Roussot-Larroque, Burnez, 1997, p. 62) (Gomez de Soto et al., 1988, p. 518, fig. 1, n 9). On le rencontre également dans la Drôme à la Baume des Anges dans un contexte du Bronze final II a (Vital, 1990, fig. 24, n 8 ; fig. 26, $n^{\circ} 3$ ). En Ile-de-France, il est recensé à Marolles-sur-Seine dans la nécropole 1 des Gours-aux-Lions, datée du Bronze final II a (Mordant, 1970, fig. 36, décor B5, p. 81). L'écuelle (fig. 11) $n^{\circ} 1$ du Petit Souper est donc un témoignage des productions à décor cannelé de la fin de la phase ancienne ou du début de l'étape moyenne du Bronze final (fin Bronze II a/début Bronze II b).

Parmi ces éléments anciens figurent également des cordons lisses (fig. 15) $n^{\circ} 9$ et 11 et surtout la petite languette de préhension recourbée (fig. 15) n 14. Pour la période considérée, cette association cordons lisses/languette de préhension est observée dans la série du Bronze final II a de la Baume des Anges dans la Drôme (Vital, 1990, fig. 33 et 35); par contre, pour ce même site, la période suivante (Bronze final II b) voit une raréfaction du cordon et une disparition des éléments de préhension. D'une façon plus générale, la languette de préhension semble étrangère aux corpus Bronze final II $b$.

Le vase surbaissé biconique (fig. 11) n ${ }^{\circ} 12$ caractérisé par un épaulement très développé trouve de proches comparaisons dans les contextes de nécropoles. La sépulture d'Azay-sur-Cher en Indre-et-Loire a livré un petit vase aux semblables proportions (Cordier, 2009, p. 487, fig. 381). En Touraine, la typologie des vases du champ d'urnes de Chissay (Bronze final II a) présente également ce type de forme (Cordier, 2009, fig. 391, n 11), le profil est cependant moins écrasé. En Charente, cette forme figure dans l'importante série de Rancogne (Gruet, Roussot-Larroque, Burnez, 1997, pl. 5, n 1) sous l'appellation de vase à col resserré en illustration de la phase ancienne du Bronze final. Son décor, composé de cannelures légères très resserrées soulignées sur leur partie haute par trois fines cannelures horizontales, est répertorié dans le contexte du Hallstatt A1 du site de Maizières-les-Metz en Lorraine (Blouet et al., 1988, p. 198 et pl. $5, \mathrm{n}^{\circ} 5$ et 8 ).

Le décor de fines incisions ou d'impressions de la jonction épaule/bord (fig. 11) n 3 est signalé à Rancogne avec une expression similaire sur deux écuelles à bord oblique illustrant la phase ancienne du Bronze final (Gruet, RoussotLarroque, Burnez, 1997, pl. 4, n 1 et 4; p. 53 et 54).

Ce faciès ancien côtoie au sein de la fosse 37 des formes et décors typiques de la tradition RSFO. Le type générique " écuelle à épaulement et à col cylindrique " aussi désigné sous l'expression "gobelet à épaulement de type large " est représentée ici par un seul vase (fig. $11: n^{\circ} 9$ ). Ces vases apparaissent antérieurement aux gobelets à épaulement et à haut col; les versions tardives (jusqu'au Bronze final III a) voient leur col se resserrer et leur profil se rehausser (Gruet, Roussot-Larroque, Burnez, 1997, p. 60). Dans le Loiret, cette forme est signalée à Villemandeur dans un contexte Bronze final II b/III a (Villes, 1988, p. 389, fig. 3, n 15), à Nancray-sur-Rimarde dans un contexte de cimetière en champs d'urnes (Cordier, 2009, p. 459, fig. 359, n 6), à Tigy, également dans un contexte de champs d'urnes daté du Bronze final II/III. Toujours dans le Loiret, la fouille du site d'habitat de la Petite Guillerie à Guilly, daté du début $\mathrm{du}$ Bronze final II b, a livré une intéressante série d'écuelles carénées à col cylindrique (Jan, 2006, p. 36, pl. 2, n 4, $5,6,9)$. Les vases présentés montrent de nettes analogies morphologiques avec l'écuelle du Petit Souper (fig. 11) n 9. Dans le sud-ouest, l'assemblage de la grotte de Rancogne offre quelques exemplaires décorés et aux carènes moins vives, datés de la fin de l'étape ancienne ou du début de l'étape moyenne du Bronze final (Gruet, Roussot-Larroque, Burnez, 1997, p. 174, pl. 8, n 12, 15, 17, 19). Plus loin, dans la Drôme, la série Bronze final II b de la Baume des Anges présente des formes plus conformes au vase du Petit Souper; les carènes sont marquées et les surfaces ne sont pas décorées (Vital, 1990, fig. 39, n 15).

Les jarres biconiques, représentées ici par les vases (fig. 12) $\mathrm{n}^{\circ} 2$ et 3, figurent dans les corpus de l'étape moyenne du Bronze final (Les Gours-aux-Lions, Rancogne, La Baume des Anges, grotte des Planches-près-Arbois, etc.).

Le style décoratif RSFO est, par ailleurs, illustré par les motifs incomplets de décor en guirlande (fig. $9: \mathrm{n}^{\circ} 13$ et 14). On peut noter que ce sont les seuls témoins de cette technique ornementale. Leur état fragmentaire compromet tout travail de comparaison.

Dans le registre des formes ouvertes, les assiettes figurent, en général, en bonne place dans les assemblages du Bronze final II et III. Pour les exemplaires du Petit Souper, les rapprochements typologiques avec le corpus de Rancogne s'avèrent incontournables.

L'assiette (fig. 9) $n^{\circ} 1$ reprend les caractéristiques morphologiques de profils analogues de la fin de la phase ancienne ou du début de l'étape moyenne de Rancogne (Gruet, Roussot-Larroque, Burnez, 1997, pl. 9, n 1 et 3). Une autre assiette (fig. $9: \mathrm{n}^{\circ} 3$ ) adopte, presque point pour point, les traits d'un vase richement décoré de motifs au peigne provenant de la série Bronze final II b de Rancogne (Gruet, Roussot-Larroque, Burnez, 1997, pl. 14, n 1).

On remarquera pour cette série d'assiettes, l'absence de profil brisé ou de rebord décroché caractéristiques du Bronze final II b (Gruet, Roussot-Larroque, Burnez, 1997, p. 75). 
Quant aux écuelles de petits diamètres (fig. $9: \mathrm{n}^{\circ} 15$, $16,17)$, elles trouvent généralement références dans des contextes funéraires. À titre d'exemple, on peut évoquer les formes non décorées de type RSFO de la tombe $\mathrm{n}^{\circ} 13$ de la nécropole du Pralat à Broussy-le-Grand dans la Marne (Chertier, 1988, p. 245, fig. 3).

La fouille de la fosse 37 a livré deux autres types de vases de formes ouvertes : un bol à parois convexes décoré de cannelures resserrées (fig. $11: \mathrm{n}^{\circ} 7$ ) et deux fragments d'écuelles tronconiques à bord droit (fig. $11: \mathrm{n}^{\circ} 5$ et 8 ). Ces formes se généralisent à partir du Bronze final III, mais sont toutefois connues dans des ensembles plus précoces, dès le Bronze moyen. Pour la France de l'Est, la typologie des céramiques du groupe RSFO dans la région dijonnaise recense la présence de ce type de vases dans le corpus de la phase II du site du Pré-au-Plancher à Varois-et-Chaignot (Côte-d'Or) où cette phase II marquerait la transition entre le Bronze final II b et III a (Ducreux, 2007, fig. 24, p. 47). Dans le Sud, le Bronze II b de la Baume des Anges connaît également ces récipients tronconiques ou à paroi convexes (Vital, 1990, fig. 37). Le décor de doubles lignes de digitations sur la carène (fig. $14: \mathrm{n}^{\circ} 3$; fig. $15: \mathrm{n}^{\circ}$ 5) fait partie du répertoire décoratif des formes grossières de cette période (Bronze final II b) à Rancogne et la Baume des Anges.

Un petit fragment de couvercle extrait de la fosse 37 (fig. $12: \mathrm{n}^{\circ} 1$ ) possède un profil et un diamètre analogue à celui d'un exemplaire découvert dans l'inhumation 18 de la nécropole 1 des Gours-aux-Lions à Marolles-sur-Seine; ce contexte est attribué au début du Bronze final II (Mordant, 1970 , p. 36, fig. 10, n 4). Pour cette période, les représentations ou mentions de couvercles sont rares et semblent réservées aux contextes funéraires.

En ce qui concerne la céramique grossière de la fosse 37 , les longues traces digitées verticales ou légèrement obliques couvrant la partie basse des vases, du fond jusqu'à la base de l'épaule, constituent un trait caractéristique de cette production; l'application couvrante d'empreintes ponctuelles (fig. $15: \mathrm{n}^{\circ} 10$ et 13 ) est une variante décorative à cette technique. Cette méthode associant façonnage et recherche d'une esthétique est récurrente dans les séries de céramiques grossières de la première moitié de l'étape moyenne du bronze final. En Lorraine, le gisement du Bronze final de Maizières-les-Metz a livré des vases biconiques développant des décors identiques à celui du tesson (fig. 15) $\mathrm{n}^{\circ} 10$, le contexte lorrain est daté du Hallstatt A1 (Bronze final 2 a) (Blouet et al., 1988, p. 202, pl. 2, n' 1 et 3). En Charente, le corpus de Rancogne présente également ce type de décor sur des formes biconiques de la série Bronze final II (Gruet, Roussot-Larroque, Burnez, 1997, p. 184, pl. 18, no 1 et 3). Il est aussi signalé dans le Loiret sur le site des Larris 1 à Échilleuse pour lequel l'occupation s'étend du Bronze final
I au Bronze final III (Simonin, 1982, p. 32, fig. 7). Pour les contextes Bronze final de Basse-Normandie, ce type de traitement de surface est considéré comme " un élément datant et est comparable tout à fait aux céramiques du gisement Bronze final de Runnymede Bridge en Angleterre » (Marcigny et al., 2005, p. 321).

La morphologie des bords se prête également à quelques comparaisons; ainsi, des bords complexes (fig. $14: \mathrm{n}^{\circ} 2$ et 5), caractérisés par leur rupture verticale interne, trouvent une comparaison presque exacte dans le corpus du début du Bronze final II b du site de la Petite Guillerie à Guilly dans le Loiret (Jan, 2006, pl. 14, $\mathrm{n}^{\circ}$ 1). Le vase (fig. 14) $\mathrm{n}^{\circ} 2 \mathrm{du}$ Petit Souper reprend toutes les caractéristiques morphologiques et ornementales de cet exemplaire. Dans le même esprit, le bord d'un autre vase du Petit Souper (fig. $14: \mathrm{n}^{\circ} 1$ ) présente une rupture verticale interne ainsi qu'un méplat sur son extrémité; cette description s'applique aussi aux bords (fig. 16) $n^{\circ} 1,2$ et 3 ; cela permet d'établir, là encore, un parallèle très proche avec un exemplaire de la Petite Guillerie (vase $\mathrm{n}^{\circ} 3$, p. 49, pl. 15). Dans cette optique, cela pourrait illustrer prudemment l'idée d'une aire d'identité culturelle qui serait structurée par l'axe ligérien et ses affluents (le site la Petite Guillerie se trouve à environ 2 kilomètres du fleuve).

\section{Chronologie}

La fosse 37 a bénéficié d'une datation C 14 réalisée sur un échantillon de charbon prélevé dans l'us 2 (code LY-14472) : âge $14 \mathrm{C} \mathrm{BP}$ : $-2920 \pm 35$; âge calibré : 1257 à 1009 av. J.-C.; date la plus probable : 1122 av. J.-C.

Selon la chronologie proposée par W. Kimmig, cette date correspondrait à la charnière Bronze final II a/Bronze final II b (Kimmig, 1988, p. 15).

L’analyse typologique des formes et décors a mis en évidence la coexistence d'éléments trouvant référence dans les corpus Bronze final II a et Bronze final II b. À ce titre, il convient de reprendre les conclusions de l'étude sur le site de transition Hallstatt A1/A2 de Maizières-Les-Metz en Lorraine et les considérations plus larges sur les innovations ou perdurations de formes et décors dans le bassin de la Moselle (Blouet et al., 1988, p. 198).

Le Hallstatt A1 de Lorraine connaît les écuelles à décor interne en association avec des motifs cannelés semblables à celui ornant l'un des vases de la fosse 37 (fig. $11: \mathrm{n}^{\circ} 12$ ). Par ailleurs, ce contexte présente " tous les intermédiaires entre le gobelet biconique de type $\mathrm{Ha} \mathrm{A} 1$ et le gobelet à épaulement Ha A2 » (p. 198). Ces réflexions s'appliquent à l'assemblage de la fosse 37 du Petit Souper. Par ailleurs, la présence d'éléments indéniablement anciens (décor cannelé en panneaux verticaux et horizontaux, languette de préhension, cordons lisses), en association avec des formes qui ont perduré durant l'étape moyenne du Bronze final, permet de 
us 1 et 2
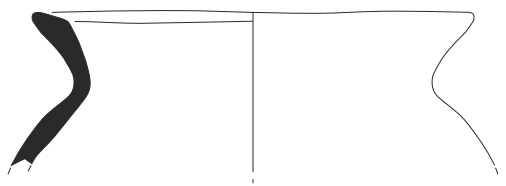

)

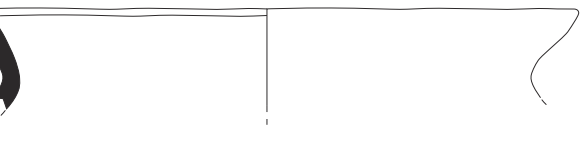

)
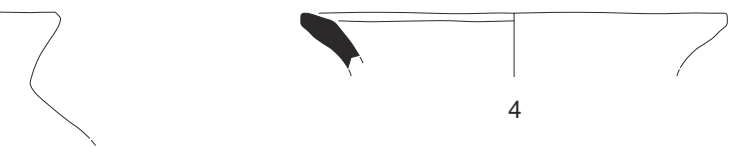

4
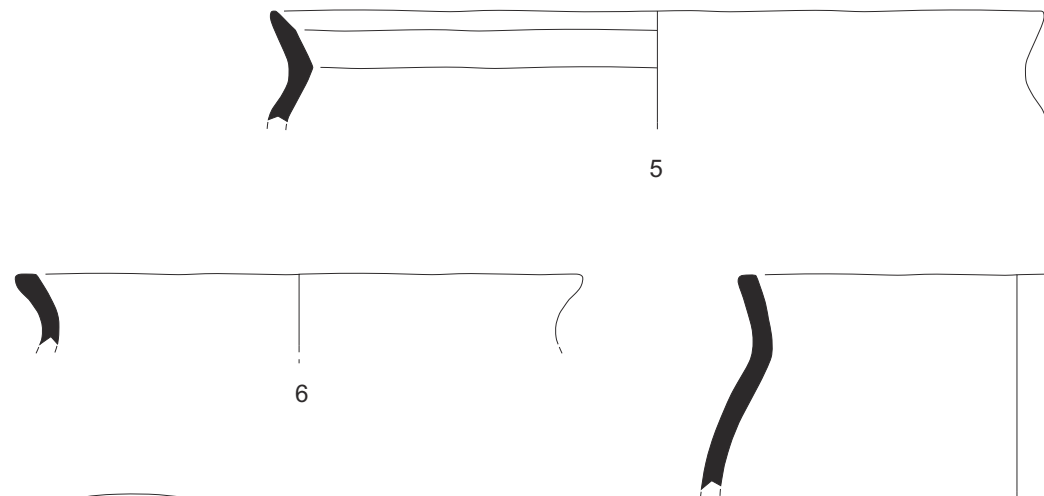

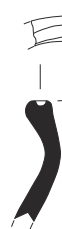
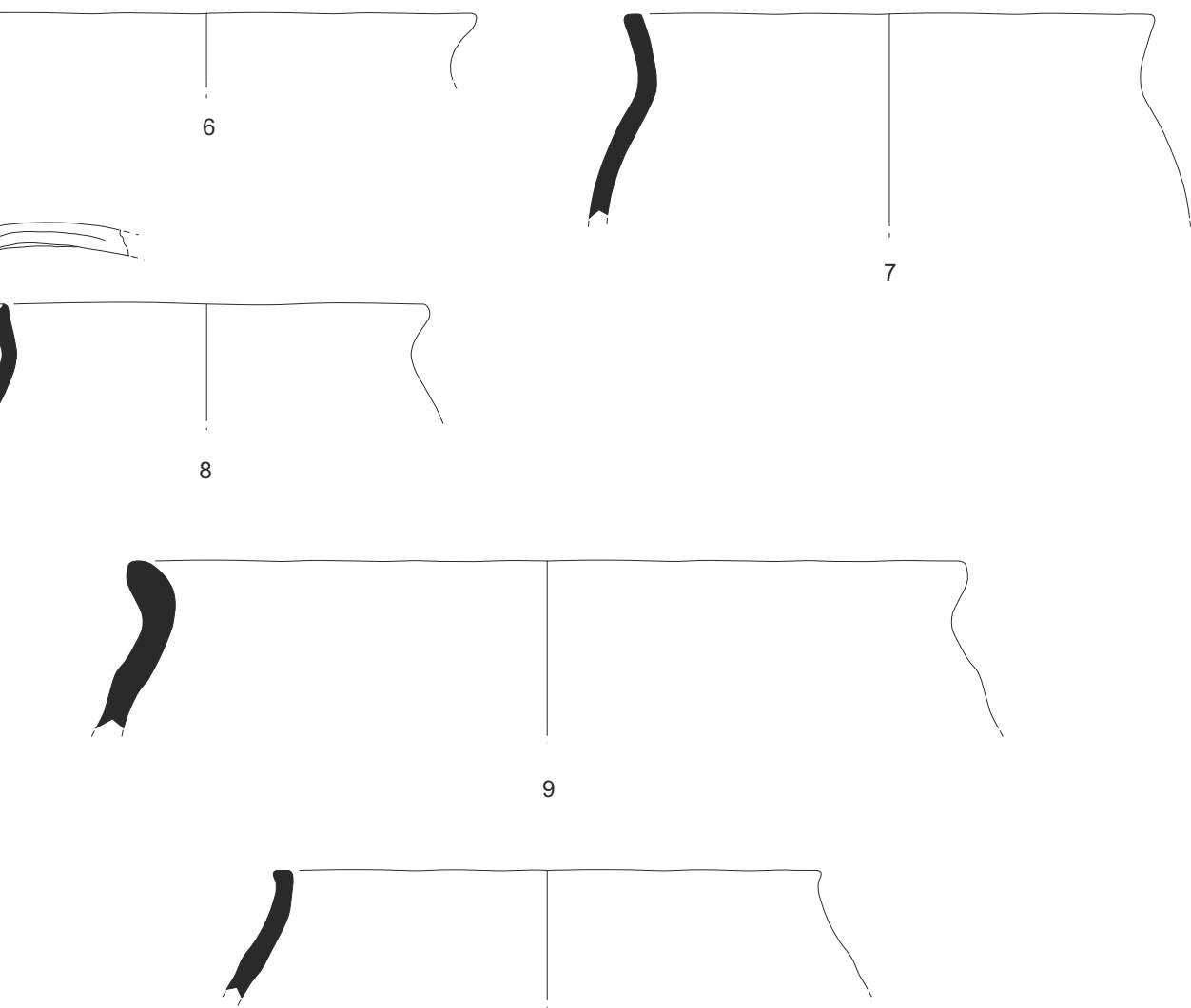

10

\section{$0 \longrightarrow-5 \mathrm{~cm}$}

Figure 16 : Le Petit Souper, fosse 37, céramique grossière (DAO : H. Hostein).

Figure 16: Le Petit Souper, pit 37, coarse ceramics (DAO: H. Hostein). 

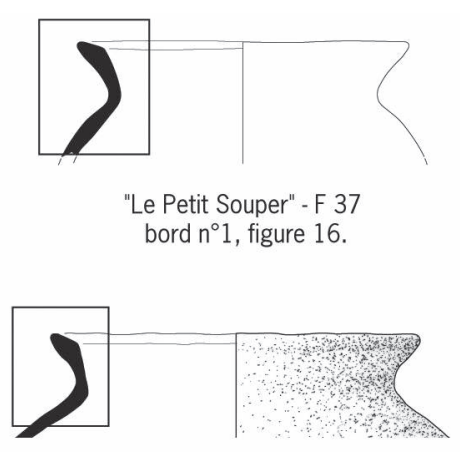

"Le Petit Souper" - F 37 bord $n^{\circ} 1$, figure 14 .

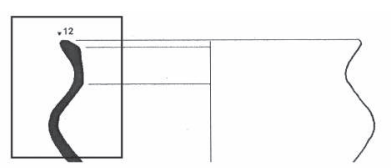

Guilly - "La Petite Guillerie", planche $3, n^{\circ} 1$.

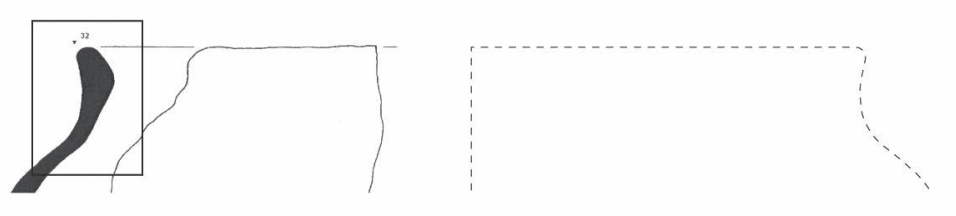

Guilly - "La Petite Guillerie", planche 15, n³.

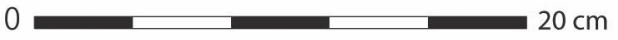

Figure 17 : Le Petit Souper, fosse 37, planche de comparaison, bords de céramique grossière (DAO : H. Hostein).

Figure 17: Le Petit Souper, pit 37, comparison, coarse ceramics edges (DAO: H. Hostein).

proposer une datation précoce pour ce corpus de la fosse 37 soit : fin du Bronze final II a, début du Bronze final II b. Cette conclusion étayée par l'analyse typologique et les comparaisons avec les corpus de référence correspond au résultat de la datation $\mathrm{C} 14$.

\section{Ensemble 41 (F 41, 80, 88, 90) : formes et décors (fig. 18, 19, 20).}

\section{Description technique}

L'assemblage est caractérisé, en valeur absolue, par une forte prédominance des tessons en pâte grossière (93\%). Les pâtes semi-fines représentent donc un peu plus de $7 \%$ du corpus, les pâtes fines sont absentes de cette série. La distinction fine et semi-fine s'appuie sur la présence ou l'absence de dégraissant et le soin apporté au traitement des surfaces. Une pâte semi-fine peut contenir une proportion notable de dégraissant fin et calibré, les surfaces sont soignées.

Au-delà de la typologie des formes et décors, l'examen visuel des pâtes de cet ensemble montre, d'emblée et de façon particulièrement évidente, la présence d'un type de pâte grossière (groupe 1) qui est totalement absent de la série de la fosse 37 . Le terme de pâte grossière s'applique parfaitement à ces tessons. Les surfaces sont très irrégulières et la finition reste très sommaire. Le dégraissant est constitué de nombreux graviers émoussés, certains d'entre eux atteignent $10 \mathrm{~mm}$ de long. Ces tessons présentent un cœur gris et une surface externe beige. Cette description concerne les vases et décors suivants : pour F41 : fig. $18: \mathrm{n}^{\circ} 1,4,5,6$ et pour F 90 : fig. $20: n^{\circ} 2$.

Un autre type de pâte grossière (groupe 2) est rencontré dans cette série. La pâte est grise, les surfaces sont rugueuses; le dégraissant, constitué de petits graviers, est abondant et calibré. Les parois sont peu épaisses. Le cœur de la pâte est gris, les surfaces ont une teinte brune. Ce type concerne les formes suivantes : fig. $18: \mathrm{n}^{\circ} 2$; fig. $19: \mathrm{n}^{\circ} 1$ et 3 .

Le bord (fig. 19) $\mathrm{n}^{\circ} 4$ est réalisé avec une argile de texture très sableuse, grise au cœur et brune à ocre en surface (groupe 3).

Aucune des caractéristiques des pâtes grossières de F 37 ne se retrouve dans cet assemblage.

Les pâtes semi-fines sont de teinte grisâtre; le bord d'assiette (fig. 19) $n^{\circ} 5$ présente une pâte légèrement micacée.

\section{Vases en pâte grossière : formes et décors}

Les profils sont fluides, peu segmentés sur leur partie haute. Les bords sont droits, leur architecture est dénuée de recherche stylistique. Les diamètres des vases peuvent être conséquents (fig. $18: \mathrm{n}^{\circ} 1$ et 4 ; fig. $20: \mathrm{n}^{\circ} 2$ ). Le pot à profil sinueux apparaît dans cette série (fig. $19: n^{\circ} 3$ ). Les différences morphologiques et techniques entre les productions de l'ensemble F 41 et celles de la fosse 37 sont donc flagrantes. L'élaboration biconique des productions de F 37 laisse ici la place à des formes simples, peu décorées. Lornementation par digitations, voire double lignes de digitations (fig. $18: \mathrm{n}^{\circ} 7$ ) subsiste cependant pour quelques vases, mais elle ne revêt pas le caractère presque systématique de la typologie ornementale des formes grossières de F 37.

\section{Vases en pâtes semi-fines: formes et décors}

Le bord de forme ouverte (fig. 19) $n^{\circ} 6$ adopte un profil tronconique. Son bord droit est bien individualisé du corps du vase, il a été façonné par un pliage de la pâte vers l'intérieur du vase. Le diamètre n'a pu être calculé; cependant, le 

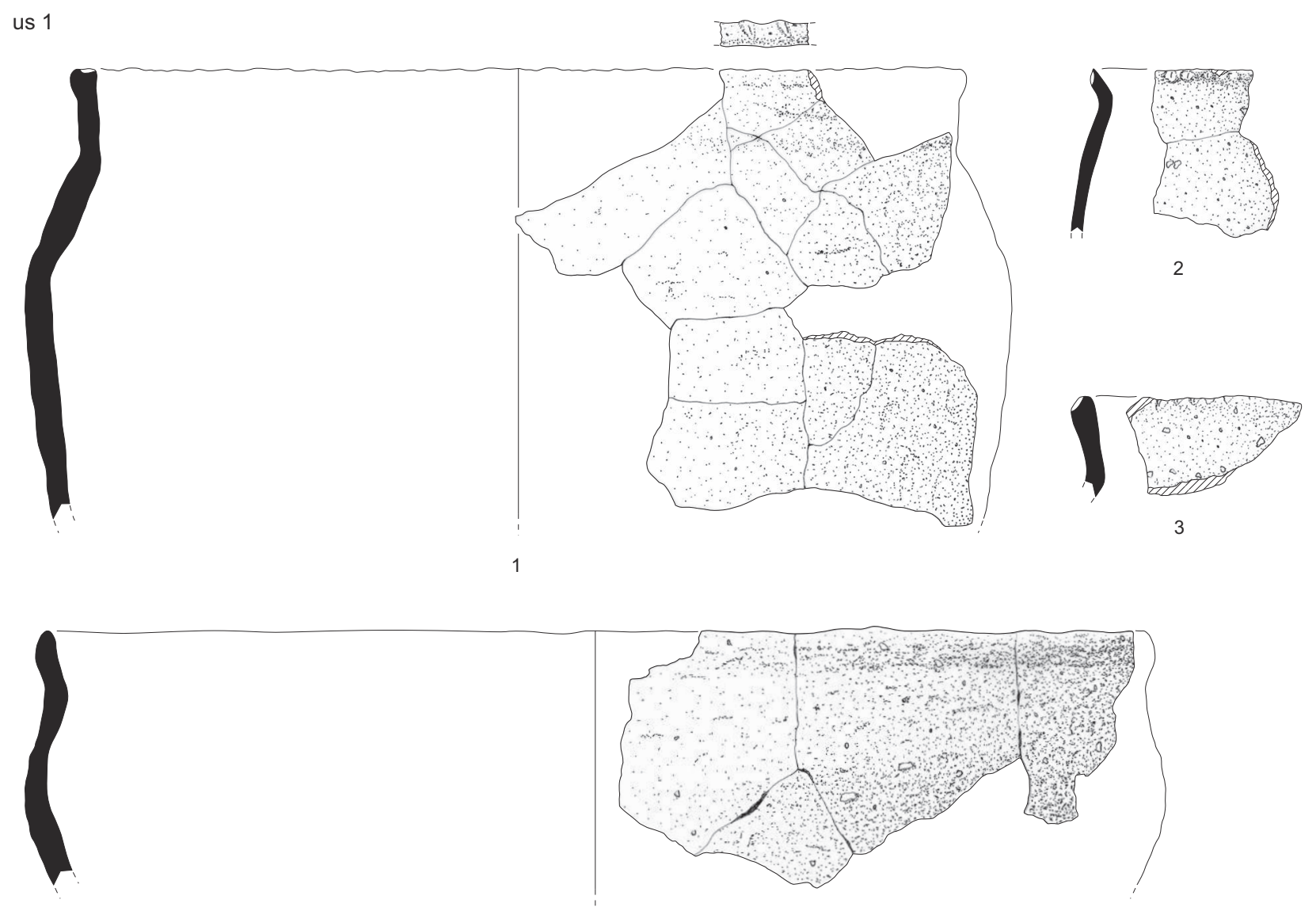

4

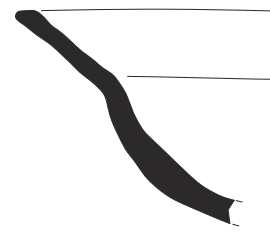

$0--5 \mathrm{~cm}$

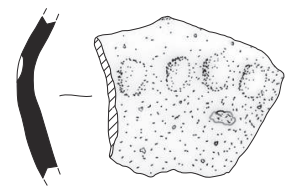

6

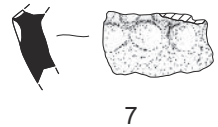

7

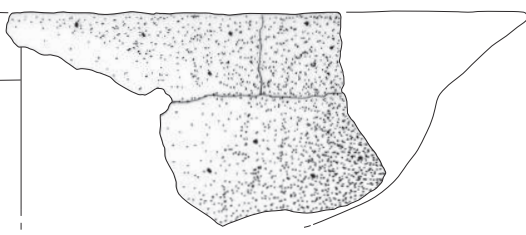

Figure 18 : Le Petit Souper, fosse 41, céramique grossière (DAO : H. Hostein).

Figure 18: Le Petit Souper, pit 41, coarse ceramics (DAO: H. Hostein).

dessin du profil permet d'assimiler cette forme à la catégorie des jattes à bord vertical.

Le vase (fig. 19) $n^{\circ} 7$ présente une carène affirmée et un épaulement assez court, presque vertical. Le bord est manquant, mais son amorce subsiste; l'orientation des parois permet d'écarter l'hypothèse de la naissance d'un col. Une cannelure, large de $2 \mathrm{~mm}$ et assez profonde, souligne la naissance de ce bord. Au niveau de la ligne de carène, le diamètre du vase d'origine est de $23 \mathrm{~cm}$. La nature très fragmentaire de ce vase compromet une identification avérée; mais, la restitution graphique du vase d'origine laisse entrevoir une forme de type jatte carénée.

L'assiette (fig. 19) $\mathrm{n}^{\circ} 5$, dont seul le bord avec l'amorce de la paroi a été conservé, se distingue par une orientation abrupte du profil. La forme tronconique est marquée par sa profondeur. D'autre part, on peut remarquer la forme très allongée de sa lèvre.

Le bord oblique cannelé (fig. 20) $n^{\circ} 3$ est attribuable à une petite écuelle à bord oblique de 16 à $17 \mathrm{~cm}$ de diamètre. La surface de ce vase a été lissée. 
us 1 et 2
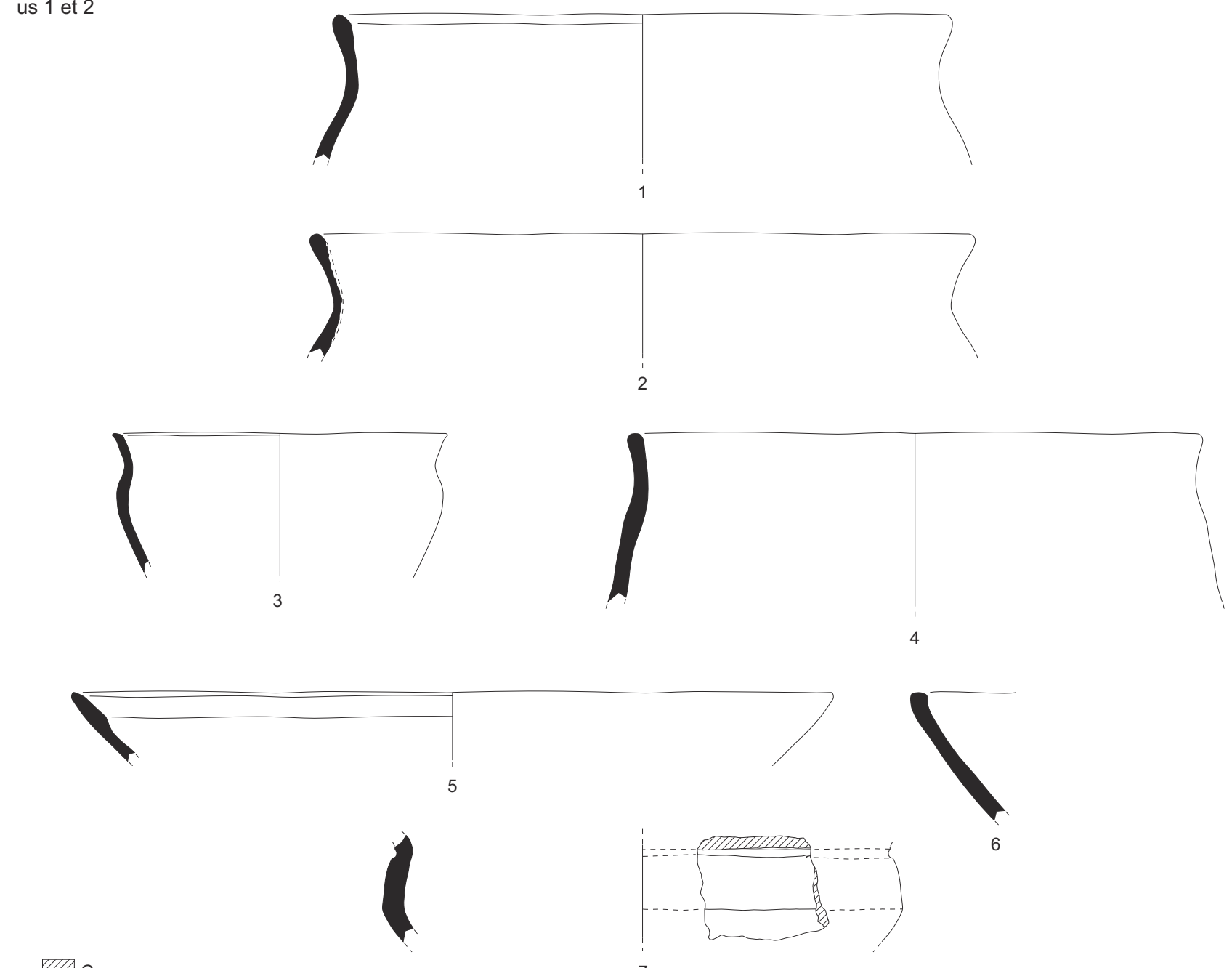

Cassure
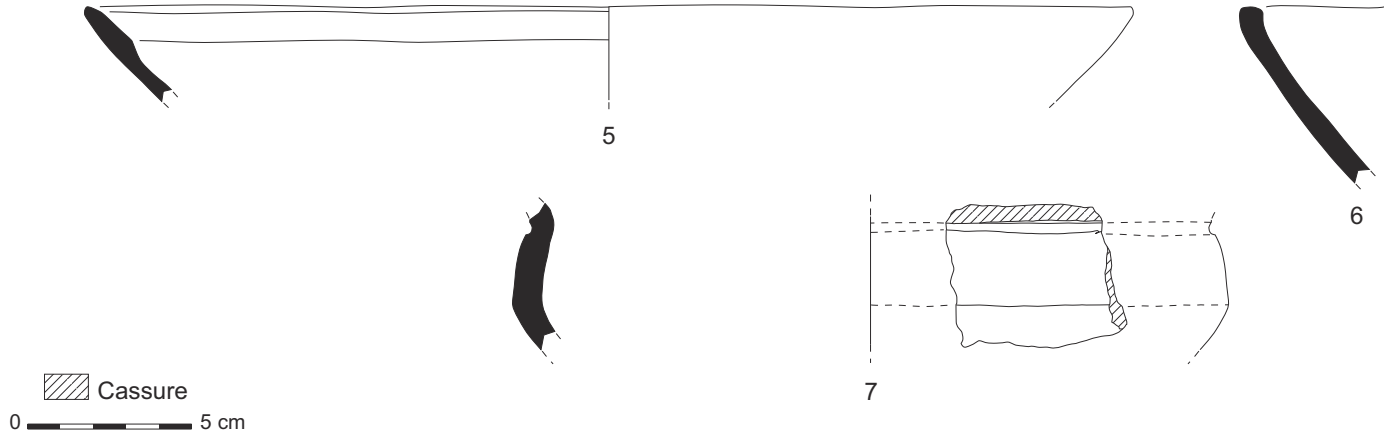

6

Figure 19 : Le Petit Souper, fosse 41, céramique semi-fine et grossière (DAO : H. Hostein).

Figure 19: Le Petit Souper, pit 41, semifine and coarse ceramics (DAO H. Hostein).

\section{Comparaisons et attributions chronologiques}

En ce qui concerne le fragment d'écuelle tronconique à bord droit (fig. 19) $n^{\circ} 6$, la littérature archéologique reconnait l'apparition précoce, dès le Bronze moyen, des récipients tronconiques avec ou sans segmentation haute. Les auteurs notent une généralisation de ce profil au Bronze final III a (Vital, 1990, p. 88); (Piningre, 2005, p. 153).

Le bord d'assiette (fig. 19) $\mathrm{n}^{\circ} 5$ se singularise par la forme et la longueur de sa lèvre amincie. Cette morphologie trouve une exacte comparaison dans le corpus Bronze final III b du site de La Croix-Saint-Ouen « Parc Scientifique » dans la vallée de l'Oise (Blanchet, Talon, 2005, p. 249, fig. 18, st. 10). Mais, une similitude tout aussi exacte peut être établie avec un bord d'assiette du site de Choisey "Aux Champions ", dans le Jura pour un contexte Bronze final II b (Bourson, 2006, pl. 3, n 1 ).

Sur le site de La Croix-Saint-Ouen, l'association de ce type d'assiette avec un vase à profil sinueux semblable au vase (fig. 19) $\mathrm{n}^{\circ} 3$ peut être relevée (Blanchet, Talon, 2005, p. 251, fig. 5). Cependant, le corpus du Bronze final II b du Fort-Harrouard dans l'Eure-et-Loir présente aussi un profil analogue (Mohen, Bailloud, 1987, pl. 59, B 296, n 17). Dans la région de Dijon, pour la série du site du Pré-duPlancher à Varois-et-Chaignot, l'apparition du vase à profil sinueux est placée dans la phase II de l'occupation du site; cette période "présente la particularité d'associer des caractéristiques du Bronze final II b à des éléments d'un profil plus tardif » (Ducreux, 2007, p. 69). Le vase à profil sinueux 


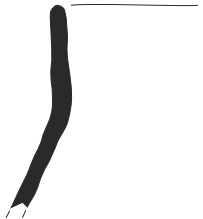

1

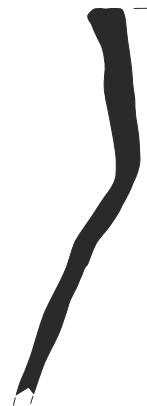

2

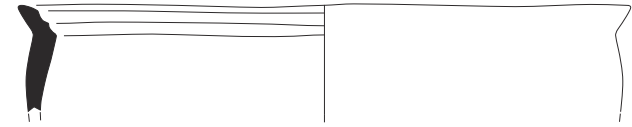

3

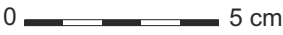

$\mathrm{cm}$

Figure 20 : Le Petit Souper, F 90 dans l'ensemble 41, céramique fine et grossière (DAO : H. Hostein).

Figure 20: Le Petit Souper, F 90 in feature 41, semifine and coarse ceramics (DAO: H. Hostein).

(fig. 19) $n^{\circ} 3$ figure, d'une façon plus générale, dans la typologie du Bronze final II $b$, perdure au Bronze final III $b$ et au-delà.

Au sujet du fragment de vase carénée (fig. 19) n $n^{\circ}$, la chrono-typologie très documentée du site du Pré-duPlancher en Bourgogne situe les jattes carénées (type 2 B) dans la phase III de l'occupation (première moitié du Bronze final III a) (Ducreux, 2007, p. 35). Le profil caréné est également signalé dans des contextes plus tardifs : la salle du Gisement de la grotte du Quéroy à Chazelles en Charente (Gomez de Soto et al., 1991, p. 365, fig. 31, n 37) présente ce type de forme. Mais, il est également présenté dans les contextes plus précoces du Bronze final II de la Baume des Anges dans la Drôme (Vital, 1988, fig. 36). La nature incomplète du fragment (fig. 19) $n^{\circ} 7$ et l'absence de décor limitent la portée des comparaisons. La chronologie peut s'inscrire dans une période allant du Bronze final II b au Bronze final III $b$.

Le bord cannelé (fig. 20) $\mathrm{n}^{\circ} 3$, issu de la fosse F 90, peut provenir d'un vase à paroi globuleuse ou légèrement segmentée sur sa partie haute, voire carénée. L'identification de ce fragment incomplet revêt donc un caractère ambigu. La comparaison peut néanmoins porter sur le "vase globuleux à petit bord déjeté " de l'abri du Chevreau à La RoqueSaint-Christophe sur la commune de Peyzac-le-Moustier (Périgord) (Roussot-Larroque, 1988, p. 496, fig. 8, n 11), ce contexte est daté du Bronze final III a. Pour la phase ancienne ou le début de la phase moyenne du Bronze final, le corpus du site Les Terres du Terrier à Maillot dans l'Yonne offre un exemple de jatte dont la partie haute reprend les caractères du fragment (fig. 20) $n^{\circ} 3$ (Muller et al., 2008, fig. $4, n^{\circ} 20$ ). De la même façon, le contexte Bronze final II de la grotte des Cloches à Saint-Martin-d'Ardèche recense une jatte à bord cannelé autorisant une comparaison pertinente (Vital, 1986, fig. 8, $\mathrm{n}^{\circ}$ 12). Comme pour les formes précédentes, la chronologie de ce bord reste donc floue; elle peut s'inscrire dans l'ensemble de la phase moyenne du Bronze final.

L'expression ornementale de la céramique grossière de l'ensemble 41 est relativement atone. Cependant, on relève la présence d'un décor de doubles lignes digitées (fig. 18 : $\mathrm{n}^{\circ} 7$ ), thème récurrent dans les séries Bronze final II $b$ et présent dans la série de la fosse 37 mais absent des répertoires décoratifs Bronze final III. D'autre part, pour le bronze final III b, la morphologie de la partie haute des vases s'oriente vers une forte segmentation de la jonction épaule/bord; cette particularité n'est pas observée pour les vases de l'ensemble 41. Ces remarques permettent d'éloigner cet ensemble de l'horizon typologique du Bronze final III b. Dans le même esprit, l'orientation biconique des formes de la fin du Bronze final II a et du début du Bronze final II $b$ de la fosse 37 n'est pas reprise par les formes grossières de l'ensemble 41. Enfin, on peut relever l'analogie du profil segmenté de la forme ouverte (fig. 18) n 5 avec 
l'exemplaire multi segmenté de type 1B2 du site du Pré-auPlancher dans la région dijonnaise; ce type 1B2 appartient à la première phase d'occupation du site datée du Bronze final II b (Ducreux, 2007, p. 34, fig. 24). Un ancrage chronologique dans le Bronze final II b semble également probable pour le vase en pâte grossière (fig. 20) $n^{\circ} 2$ qui trouve un parallèle assez proche dans le corpus d'une fosse Bronze final II b découverte sur la commune des Martres-d'Artières (Puy-de-Dôme) (Daugas, Vital, 1988, fig. 4, $\mathrm{n}^{\circ} 1$ et 2). Toutefois, les caractéristiques typologiques de ces récipients en pâte grossières peuvent aussi être rapprochées des vases de production commune du site de Malay-le-Grand «Les Bas Musats » dans l'Yonne (Muller et al., 2008, fig. 9, p. 9). La céramique issue de ce site est attribué au Bronze final III a, période bien caractérisée dans l'Est de la France.

\section{Chronologie}

Ces derniers arguments conduisent à proposer une datation Bronze final II b-III a pour cet assemblage.

\section{Fosse 43 : formes et décors (fig. 21, 22)}

\section{Description technique}

Pour cette série, les pâtes grossières rassemblent 53, $8 \%$ de l'effectif. Les faciès principaux de pâtes grossières des fosses 37 (groupe 3) et 41 (groupe 1) n'apparaissent pas dans cet ensemble. Les pâtes fines et semi-fines regroupent 46, $2 \%$ des tessons; l'altération des surfaces, observée sur les pâtes fines et semi-fines de la fosse 37, n'a pas affecté les vases de la fosse 43, les décors ont donc été préservés.

\section{Pâtes fines et semi-fines: formes et décors (fig. 21)}

Le corpus de vases en pâte fine est singularisé par trois petits vases biconiques de diamètres sensiblement équivalents (fig. $21: n^{\circ} 3,4,5$ ). L'un d'entre eux (vase $n^{\circ} 4$ ) montre, sur sa ligne de carène, deux arrachements de pâte, de forme ovoïde très régulière; au centre de l'un d'eux, transparaît l'empreinte d'un petit relief circulaire. L'hypothèse d'un éclat de pâte dû à un choc paraît douteuse; en effet, la finesse de la paroi de ce vase $(4,5 \mathrm{~mm})$ induit une faible résistance à ce type d'événement. Ces arrachements pourraient marquer, en négatif, l'emplacement de mamelons décoratifs de forme ovoïde. Toutefois, il convient de rester très prudent sur l'interprétation qu'il convient de leur accorder, le décor originel n'étant pas strictement observé. Mais, on doit remarquer que le répertoire décoratif du Bronze final II $b$ recense ce type de bouton ovoïde. Ce vase présente, en outre, un fond en cupule.

Le vase (fig. 21) $n^{\circ} 3$ trouve un homologue dans la fosse $\mathrm{n}^{\circ} 37$ (fig. 11, n 12); ici, le décor est réalisé au peigne à trois dents sans fines cannelures verticales.
Quatre fragments de bords d'assiettes possèdent cette catégorie de décor. L'amorce d'un décor au peigne est visible sur les bords (fig. 21) $n^{\circ} 6$ et 8 .

Le décor cannelé est observé sur le bord de l'écuelle surbaissée (fig. 21) n ${ }^{\circ} 1$ et à la base de l'épaulement du fragment de vase biconique (fig. 21) $\mathrm{n}^{\circ} 11$.

Le tesson (fig. 21) $\mathrm{n}^{\circ} 13$ présente sur sa face externe un décor d'incisions horizontales; deux séquences de doubles lignes entament nettement la pâte. De part et d'autre de ces deux lignes, apparaissent, plus discrètement d'autres traces similaires.

\section{Pâtes grossières : formes et décors (fig. 22)}

Au sein de cet assemblage, le vase (fig. 22) $n^{\circ} 4$ est remarquable pour le cordon digité ornant la partie haute de sa panse, au relief, en effet, particulièrement prononcé. La forme sinueuse de ce récipient est reproduite avec le vase (fig. 22) $n^{\circ} 1$. Deux vases fermés à bord droit (fig. $22: n^{\circ} 2$ et 3) ainsi qu'un vase tronconique dépourvu de segmentation, complètent cet inventaire (fig. $22: \mathrm{n}^{\circ} 5$ ). Le décor de digitations sur le côté externe de la lèvre est une caractéristique qui a été relevée sur les exemplaires de la fosse 37.

\section{Comparaisons et attributions chronologiques}

Les formes et décors recensés dans cette fosse renvoient aux référentiels du Bronze final II. Les écuelles surbaissées à bord oblique, représentées ici par l'exemplaire à bord cannelé (fig. 21) $\mathrm{n}^{\circ} 1$ apparaissent dans les séries du Bronze final II a, voire du Bronze final I et figurent dans les contextes du Bronze final II b. Par contre, ces écuelles sont absentes des corpus du Bronze final III a. Les sites pour lesquels l'occupation a été continue sur toute la période du Bronze final (Rancogne, la Baume des Anges) témoignent de cette évolution.

Le profil du vase (fig. 21) $\mathrm{n}^{\circ} 3$ est présent dans la fosse 37 (vase $\mathrm{n}^{\circ} 12$, fig. 11); ici, le décor est constitué de cannelures horizontales au peigne. Les comparaisons établies pour l'exemplaire de la fosse 37 s'appliquent pour le vase (fig. 21) $\mathrm{n}^{\circ} 3$; la chronologie retenue s'inscrit à la fin du Bronze II a ou au début du Bronze II b.

L'interprétation des arrachements ovoïdes du vase (fig. 21) $\mathrm{n}^{\circ} 4$ peut s'appuyer sur le répertoire décoratif du site de la petite Guillerie à Guilly dans le Loiret daté du début du Bronze final II b; plusieurs écuelles à épaulement sont décorées de mamelons ovoïdes en association avec des cannelures verticales (Jan, 2006, p. 37 et 38). Le motif ovoïde, disposé par paire et sans association de décor intercalaire, figure sur la ligne de carène d'un petit vase ovoïde de la série Bronze final II a de la Baume des Anges (Vital, 1990, p. 61, fig. 25, $\left.\mathrm{n}^{\circ} 7\right)$. Certains vases provenant de la nécropole $\mathrm{n}^{\circ} 1$ des Gours-aux-Lions, datée du début du Bronze final II, sont 
us 1
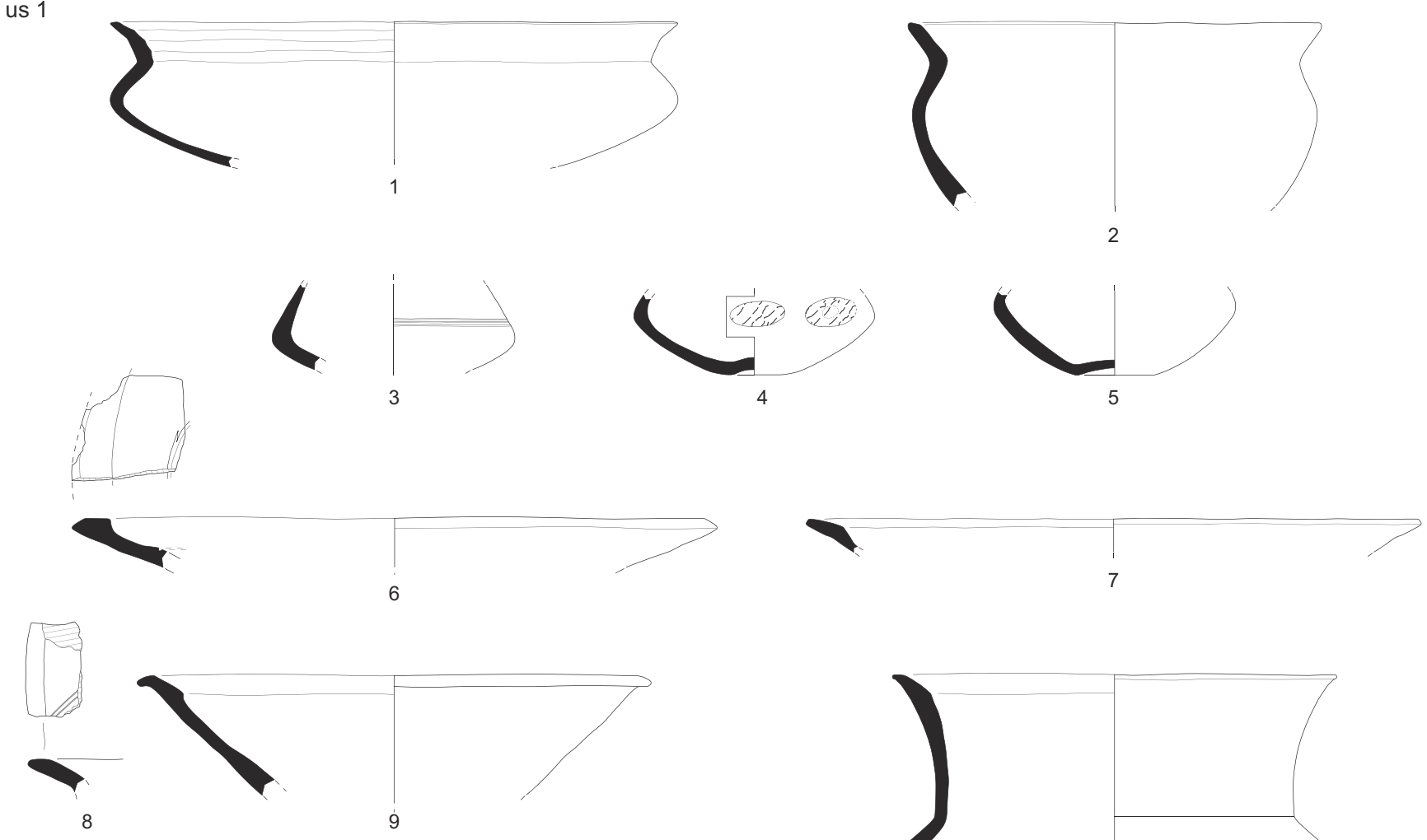

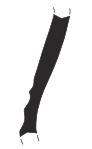

Arrachement Cassure

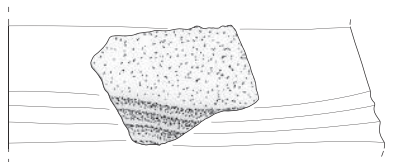

11

$0=5 \mathrm{~cm}$
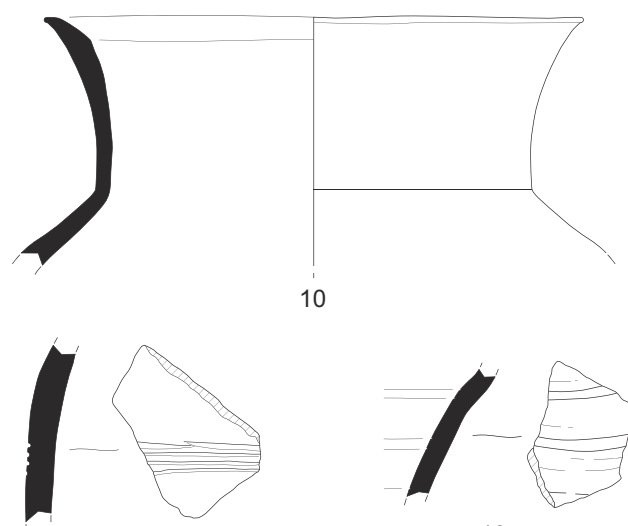

12

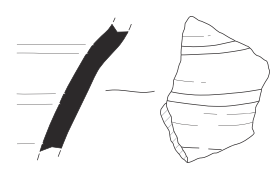

13

Figure 21 : Le Petit Souper, fosse 43, céramique fine et semi-fine (DAO : H. Hostein).

Figure 21: Le Petit Souper, pit 43, fine and semifine ceramics DAO: H. Hostein).

ornés de mamelons ovoïdes (Mordant, 1970, pl. 36 et 37). En conclusion, ce motif décoratif est très courant au Bronze final I b et surtout au Bronze final II a.

Le décor de très fines lignes incisées du tesson (fig. 21) $\mathrm{n}^{\circ} 13$ est fragmentaire; d'emblée, il fait référence à un thème décoratif mis en œuvre au Bronze final III a et III b, principalement sur des jattes : le décor de méandre, grecques ou lignes brisées. Cependant, la présence de segments de lignes horizontales parallèles aux deux motifs principaux semble contrarier cette interprétation; ces traces connexes restent cependant plus discrètes.

Le vase au profil sinueux (fig. 22) n $n^{\circ} 4$ est orné d'un cordon digité particulièrement proéminent. Ce thème décoratif répandu au Bronze ancien et surtout au Bronze moyen, se maintient au début du Bronze final jusqu'au Bronze II a. Par contre, lors de l'étape moyenne du Bronze final, son usage tend à s'atténuer au profit de motifs digités appliqués directement sur la paroi, le plus souvent au niveau de la ligne de carène ou à la base de l'épaulement. Le corpus de la grotte des Cloches à Saint-Martin-d'Ardèche présente un vase de grand diamètre adoptant le profil sinueux et décoré de digitations sans cordon appliqué (Vital, 1986, p. 522, fig. 11, $\mathrm{n}^{\circ} 1$ ). La grotte de la Baume des Anges dans la Drôme offre, pour l'horizon II a, plusieurs exemples de vases décorés de cordons digités (Vital, 1990, fig. 32, n 2; fig. 35, n 35, $\left.\mathrm{n}^{\circ} 2,3\right)$. Enfin et à titre indicatif, les caractéristiques techniques de la pâte de ce vase sont tout à fait similaires à celles du profil tronconique (fig. 22) $n^{\circ} 5$. 
us 1
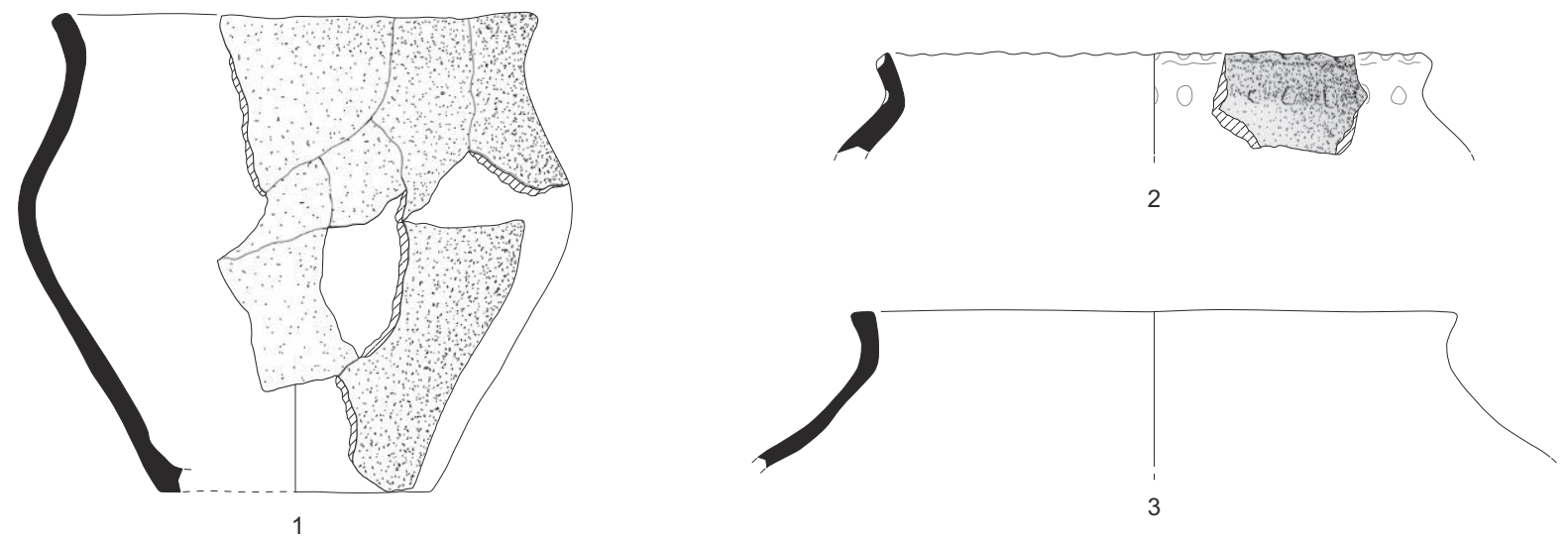

3
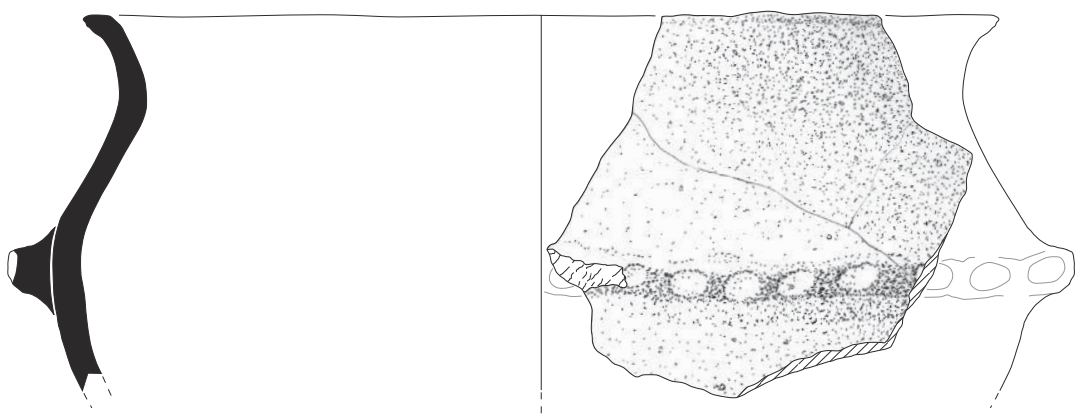

4
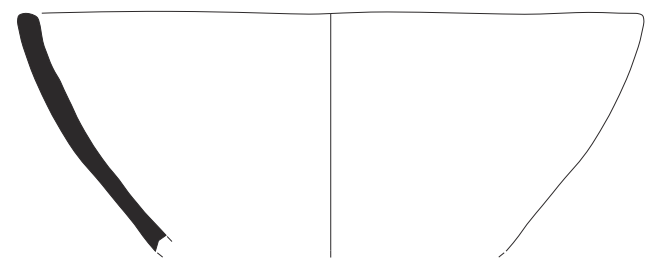

5

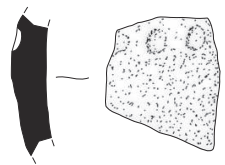

6

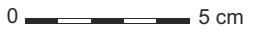

Arrachement

Cassure

Figure 22 : Le Petit Souper, fosse 43, céramique grossière (DAO : H. Hostein).

Figure 22: Le Petit Souper, pit 43, coarse ceramics (DAO: H. Hostein).

\section{Chronologie}

Compte tenu de ces éléments de comparaison, le mobilier céramique de la fosse 43 est attribuable à la fin de l'étape ancienne du Bronze final ou au début de l'étape moyenne (fin Bronze final II a/début Bronze final II b).

\section{Fosse 67 : formes et décors (fig. 23)}

\section{Description technique}

Les pâtes fines représentent, en valeur absolue, un peu plus de $31 \%$ de l'effectif. Cette catégorie est essentiellement représentée par l'écuelle large à épaulement (fig. 23) n 4 . Ce type de vase est généralement décoré; mais, cet exemplaire a subi une exposition prolongée à une source de chaleur de forte intensité et, la texture de la pâte ainsi que l'état des surfaces ont été profondément altérés. Plusieurs fragments de vases en pâte grossières présentent également les stigmates liés à de hautes températures (teinte gris souris, perte conséquente de densité, très nombreuses vacuoles).

Les pâtes grossières rassemblent $69 \%$ des restes. La fosse 67 a livré plusieurs fragments de céramique grossière présentant des caractéristiques techniques identiques à celles 
us 1
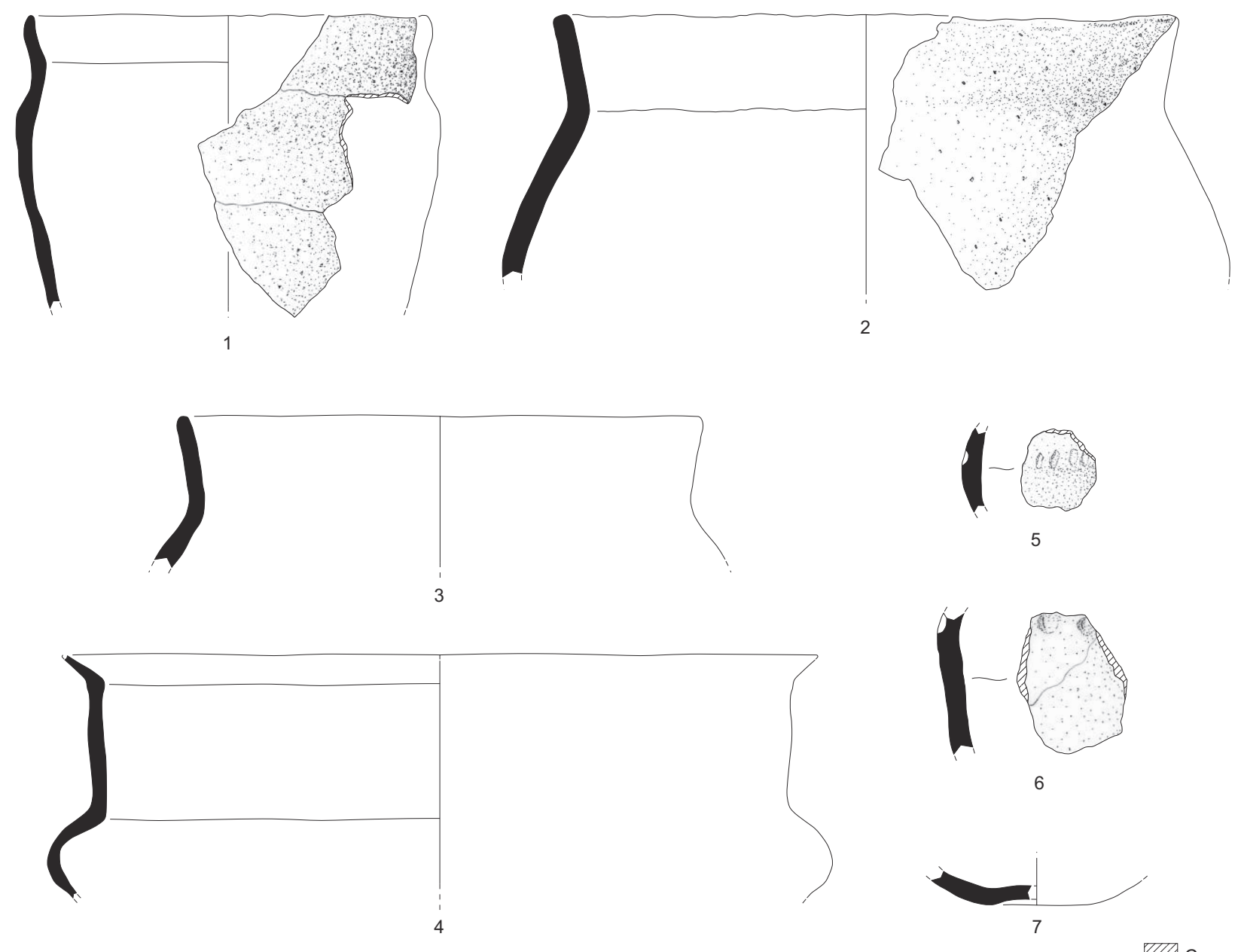

$0-5 \mathrm{~cm}$

Figure 23 : Le Petit Souper, fosse 67, céramique semi-fine et grossière (DAO : H. Hostein). Figure 23: Le Petit Souper, pit 67, semifine and coarse ceramics (DAO: H. Hostein).

des pâtes du groupe 1 de l'ensemble 41 (fig. $23: \mathrm{n}^{\circ} 1$ et 2). De même, la pâte sableuse du bord (fig. 23) n 3 et du tesson décoré (fig. 23) $n^{\circ} 5$ est, en tout point (texture, aspect visuel, dégraissant, teinte), semblable à la pâte grossière du groupe 3 de l'ensemble 41. L'examen visuel des pâtes a permis d'observer une indéniable identité technique dans la conception de deux groupes de pâtes grossières communs à l'ensemble 41 et à la structure 67 : ces deux fosses participent donc de la même phase d'aménagement puisqu'elles présentent les mêmes productions en pâtes grossières.

Pâte finelsemi-fine : vase à épaulement (fig. 23) $n^{\circ} 4$; comparaisons et attribution chronologique

Ce vase appartient à la typologie de tradition RSFO, il s'agit d'une déclinaison large du gobelet à épaulement.
Cette forme est connue dans le contexte Bronze final III a de la grotte des Planches-près-Arbois dans le Jura sous la désignation de gobelet à épaulement, du type large (Barbier et al., 1981, p. 174, fig. 20).

Sur le flanc sud du massif du Jura, le contexte d'habitat lacustre du site de Hauterive-Champréveyres (Suisse) a livré de semblables gobelets larges à épaulement; la datation proposée pour l'assemblage céramique de ce site s'insère dans " un Ha A2 évolué, commençant sa transition vers le style Ha B1» (Rychner, 1988, p. 126; fig. 4, nº 13 et 15).

Le gobelet large à épaulement est aussi un élément constitutif des corpus du Bronze final II b, il figure dans la série du Bronze final II b du site de la Maniriat à Pommiers-en-Forez dans le Massif Central (Daugas, Vital, 1988, fig. 3, n 11). 


\section{Chronologie}

L'identité de deux groupes techniques de pâte grossière appartenant aux fosses 41 et 67 , a été soulignée plus haut. Les conclusions portant sur le mobilier de la fosse 41 s'appliquent donc ici. Le mobilier de la fosse 67 est attribuable au Bronze final II b/III a.

\section{Fosse 68 (fig. 24)}

La seule forme restituée est celle d'un vase biconique présentant sur l'épaulement une série de trois cannelures horizontales assez larges, au tracé irrégulier (fig. $24: \mathrm{n}^{\circ} 1$ ). L'amorce du fond est conservée et l'orientation de la paroi à

us 1
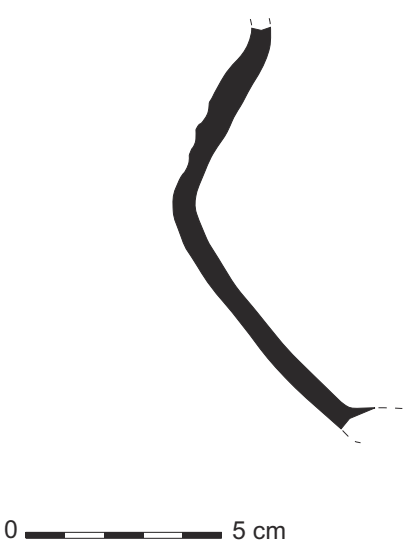

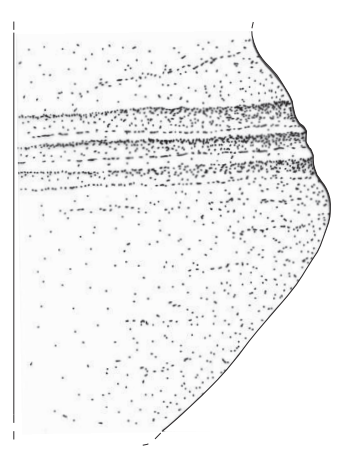

1
Figure 24 : Le Petit Souper, fosse 68, céramique semi-fine et grossière (DAO : H. Hostein).

Figure 24: Le Petit Souper, pit 68, semifine and coarse ceramics (DAO: H. Hostein). l'approche du bord laisse envisager un bord oblique. La pâte de ce vase est grise, la surface bien régularisée.

\section{Chronologie}

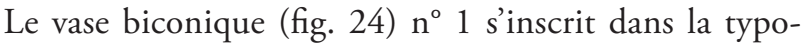
logie du Bronze final II b et du Bronze final III a. À titre d'exemple, un vase biconique présentant un décor de cannelures sur l'épaule est présenté dans la série Bronze final II b des Martres-d'Artières dans le Puy-de-Dôme (Daugas, Vital, 1988, fig. 5 , n$^{\circ} 14$ et 15). Le corpus Bronze final III a de la grotte des Planches-près-Arbois dans le Jura recense plusieurs vases biconiques, certains décorés de cannelures sur l'épaulement (Barbier et al., 1981, fig. 29, n 1). L'attribution chronologique de ce vase s'insère dans la période Bronze final II b/Bronze final III a.

\section{Fosse 62 (fig. 25)}

La fosse 62 a livré une forme archéologiquement complète, ainsi que deux bords d'assiettes. Un fond de micro vase et un fragment de récipient de grand diamètre, décoré de digitations, complètent ce petit lot de céramique très atypique. Un prélèvement de charbon effectué dans cette fosse a fait l'objet d'une datation C 14. Le résultat (code LY-14473) présente les données suivantes : âge 14 C BP : $2940 \pm 35$ av. J.-C.; âge calibré : 1263 à 1042 av. J.-C.; dates les plus probables : 1145,1128 av. J.-C. Cette datation est très proche de celle réalisée sur l'échantillon de charbon de la fosse 37. Le mobilier de la fosse 62 est donc attribuable à la fin de l'étape ancienne ou au début de l'étape moyenne de Bronze final.
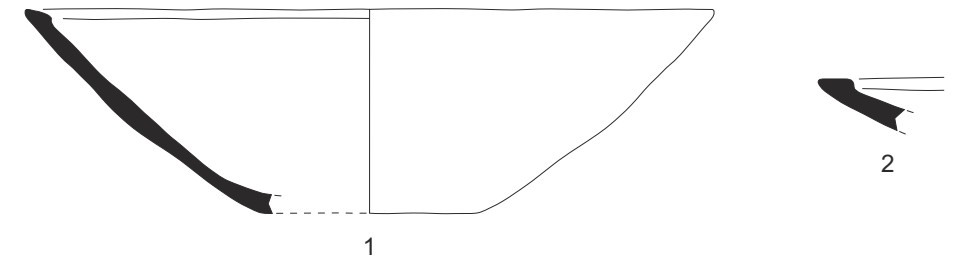
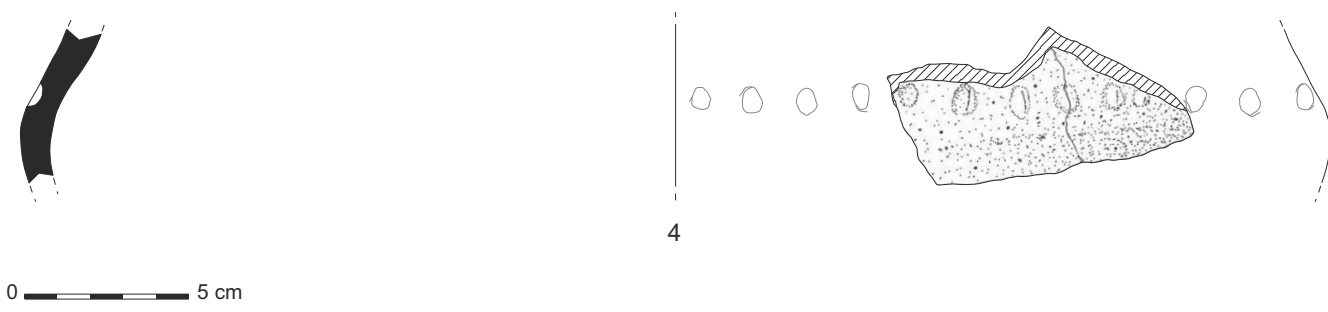

Figure 25 : Le Petit Souper, fosse 62, céramique semi-fine et grossière (DAO : H. Hostein). Figure 25: Le Petit Souper, pit 62, semifine and coarse ceramics (DAO: H. Hostein).
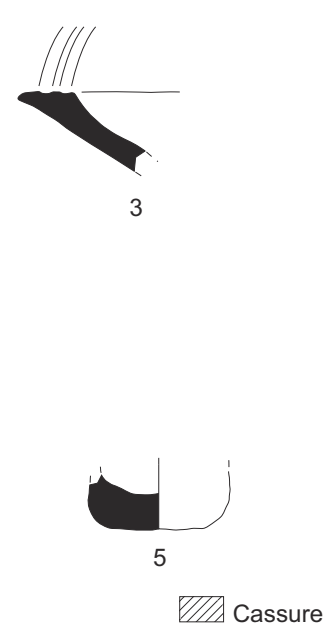


\section{Le mobilier issu des autres contextes}

Pour la fosse 14, on peut remarquer l'analogie entre le bord de l'assiette (fig. 26) $n^{\circ} 1$ et les bords (fig. 9) $n^{\circ} 15$ et 16 extraits de la fosse 37.
Parmi le mobilier issu de la fosse 39, la présence d'un bord d'assiette tronconique (fig. $26: \mathrm{n}^{\circ} 11$ ) autorise une attribution chronologique dans la phase moyenne du Bronze final. On peut cependant remarquer que les corpus du premier Âge du Fer connaissent, notamment pour les récipients tron-

F 14
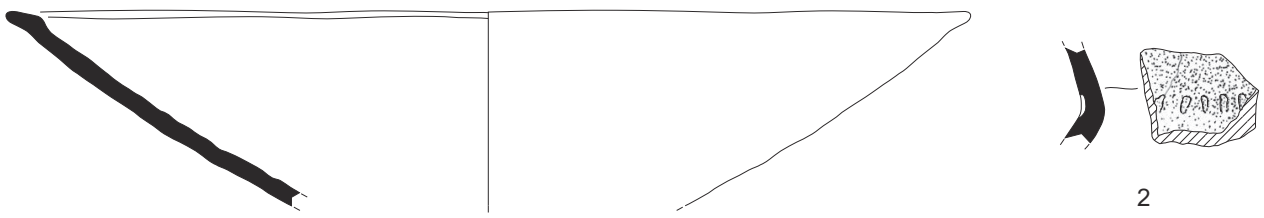

2

1

F 25

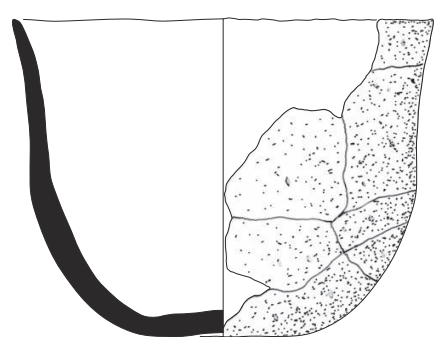

3

F 38
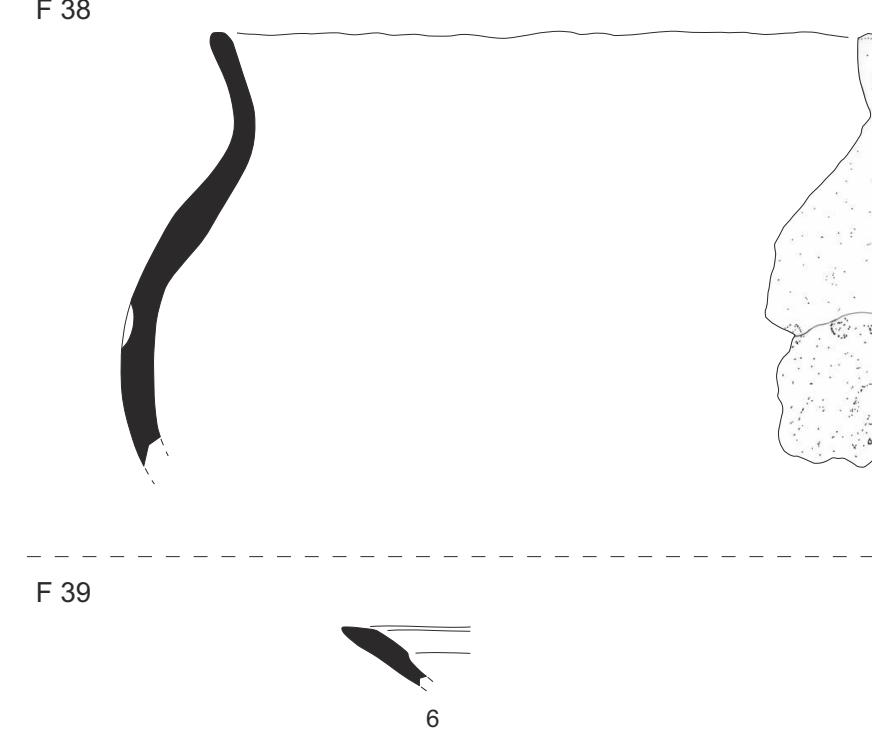

6

F 80

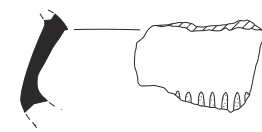

$0-5 \mathrm{~cm}$
F 27

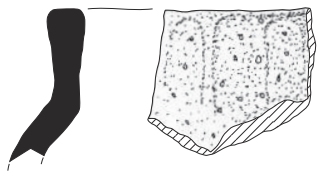

4

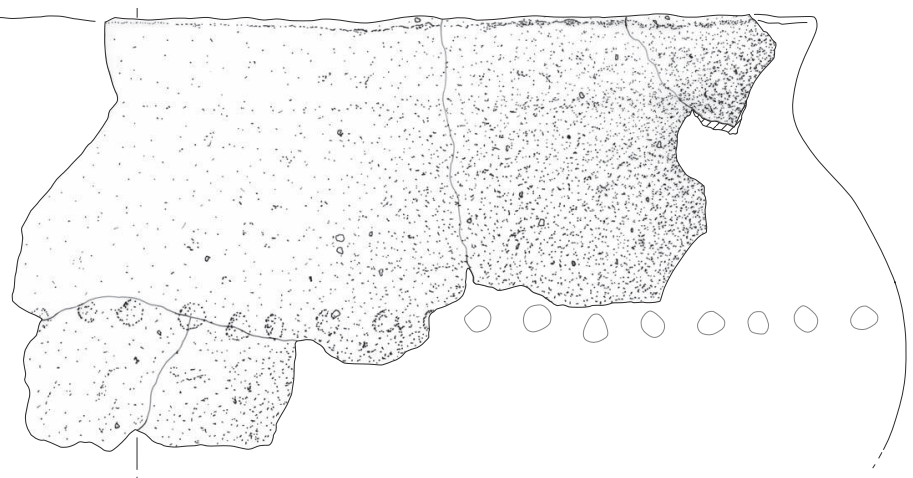

5

F 40

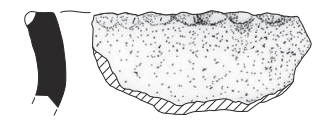

7

F 115

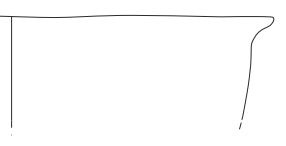

9

Figure 26 : Le Petit Souper, structures diverses, céramique fine à grossière (DAO : H. Hostein).

Figure 26: Le Petit Souper, various features, ceramic fine at coarse (DAO: H. Hostein). 
coniques mais aussi pour d'autres formes, des vases typologiquement très proches de ceux du Bronze final.

Pour la structure 80 , un seul fragment est identifiable (fig. $26: n^{\circ} 8$ ). Il s'agit d'une écuelle à bord oblique décorée de cannelures. Il convient d'inscrire la fosse 80 dans la première phase d'occupation du Bronze final.

Le bord de forme grossière (fig. 26) $\mathrm{n}^{\circ} 5$ issu de la structure $\mathrm{F} 38$ a été réalisée à partir d'une pâte présentant toutes les caractéristiques techniques du groupe 3 de la fosse 41, datée de l'étape moyenne du Bronze final (Bronze final II b/III a).

Enfin, le vase (fig. 26) n 3 issu du fossé 25 présente un profil tout à fait atypique pour ce contexte Bronze final. En fait, il évoque la typologie campaniforme. Il pourrait correspond au type "GA 2 » du Centre-Ouest défini par L. Salanova (Salanova, 2000, p. 137, fig. 78); toutefois, en l'absence de décor, la datation de ce vase reste floue.

Les fragments de poterie issus des fosses 27, 40, 42, 115 manque de typicité et, de ce fait, contrarie l'attribution typo chronologique.

\section{Mobilier en terre cuite (hors céramique, fig. 27)}

Des fragments de pesons de forme tronconique ou pyramidale ont été retrouvés dans les fosses 37, 39, 67 et 68 . On peut relever qu'en Normandie et Outre-manche, pour la période du Bronze moyen/Bronze final I, la forme des pesons est circulaire; ces objets sont présentés comme « une des composantes des sites du Bronze moyen/Bronze final I du domaine atlantique » (Chancerel, Marcigny, Ghesquière, 2006, p. 160). La forme circulaire a été également observée dans la Somme sur le site de Wiencourt-l'Equipée dans un contexte daté de la fin du Bronze moyen et du début du Bronze final; cela illustrerait « l'influence de la culture Deverel-Rimbury sur le continent »(Blanchet, Talon, 2005, p. 161).

Par ailleurs, la fosse 67 a livré deux fragments de parois de fours.

\section{Conclusion}

L'interprétation générale du site a souffert de l'exigüité de la zone d'étude. La fouille a démontré que les vestiges se développaient, à l'évidence, hors du périmètre de décapage. Il convient de préciser que la détection du site a été contrariée, lors de la phase de diagnostic, par la présence d'une zone boisée destinée à être, en partie, conservée dans le cadre du projet d'aménagement du plateau.

Le Petit Souper peut être considéré comme un site d'habitat dont l'organisation globale n'a pu être perçue pour les
Fragments de pesons
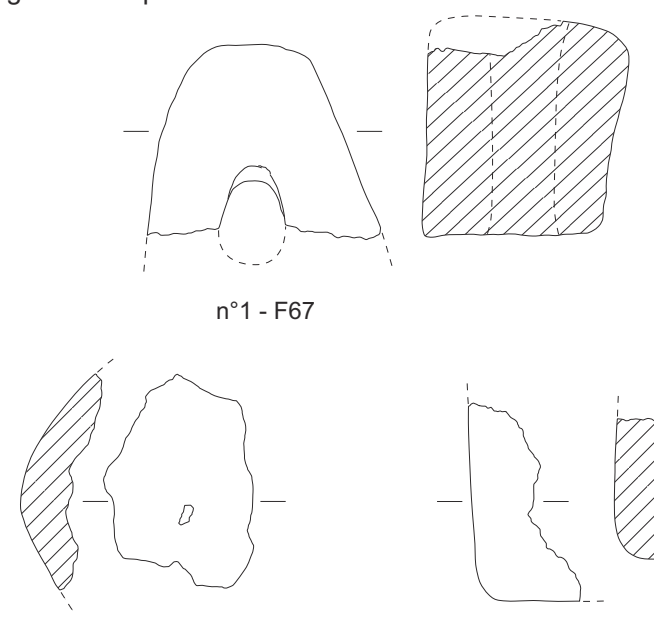

$n^{\circ} 2-F 37$

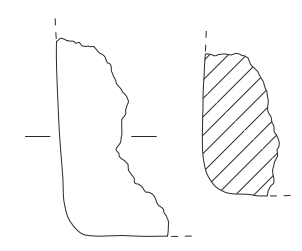

$n^{\circ} 3-F 39$

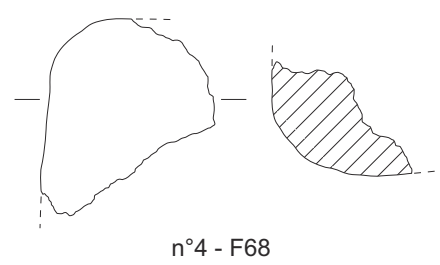

$n^{\circ} 4-\mathrm{F} 68$

Fragments de paroi de four
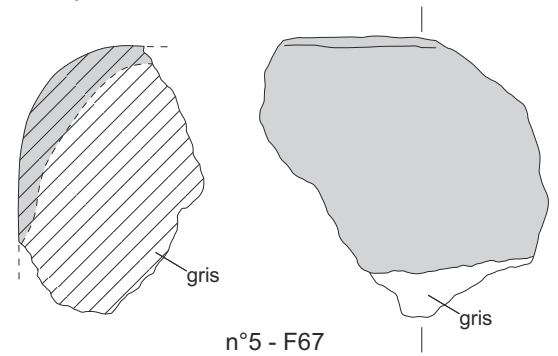

Rouge à rosé

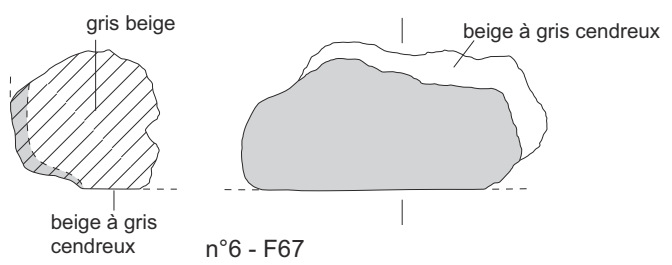

0 - $5 \mathrm{~cm}$

Figure 27 : Le Petit Souper, structures diverses, objets en terre cuite (DAO : H. Hostein).

Figure 27: Le Petit Souper, various features, artefacts (DAO: H. Hostein).

raisons qui viennent d'être évoquées; cependant, la présence, en faible quantité, d'ossements humains très brûlés est, pour le moins, intrigante. 
L'étude typologique des formes et décors des vases a permis d'établir que l'occupation attribuable au Bronze final s'installe sur le site du Petit Souper à la fin de la phase ancienne de cette période, c'est-à-dire à la fin du Bronze final II a ou au début du Bronze final II b. Le contexte le plus ancien (fosse 37 ) présente des caractéristiques typologiques relevant à la fois de la phase ancienne et de la phase moyenne du Bronze final. Le décor cannelé côtoie le décor au peigne. Cette constatation tend à accréditer la thèse d'une transition douce, sans rupture stylistique tranchée entre ces deux phases.

La seconde phase d'occupation (Bronze final II b/Bronze final III a) est illustrée par une série céramique en pâte gros- sière présentant de nettes différences typologiques et techniques avec les productions communes de la phase 1 . Le profil biconique cède la place à des formes plus hautes, plus ouvertes et de plus grand diamètre. Le registre ornemental de cette seconde phase est relativement inexpressif alors que le répertoire décoratif de la première phase (fosse 37) met en œuvre, de façon récurrente, plusieurs techniques; ainsi, le décor digité sur les lignes de segmentations hautes des profils mais aussi les traces de façonnage des vases marquent ostensiblement les surfaces externes, elles participent de l'esthétique de la production. Cette apparente rupture typologique et stylistique entre les deux phases résulte vraisemblablement d'un défaut de données intermédiaires. 


\section{Annexe 1 - Analyse anthropologique des restes osseux, Le Petit Souper, Saint-Hilaire/Saint-Florent (49)}

\section{Par Elodie Cabot, anthropologue Inrap Grand-Ouest}

La fouille du site de Saint-Hilaire-Saint-Florent a révélé la présence d'ossement brûlés dans onze fosses. Ces ossements nous ont été confiés afin d'en déterminer l'origine (humaine ou animale) et d'en effectuer une analyse.

Sur les onze fosses, seules quatre d'entre elles contenaient des restes osseux humains, pour les autres, les ossements sont d'origine animale et plus particulièrement de bovidé.

Le tableau suivant redistribue les fragments osseux en fonction de leur origine. Les fosses contenant des restes humains apparaissent en gris.

\begin{tabular}{|c|c|c|c|c|c|c|c|}
\hline \multicolumn{8}{|c|}{ Saint-Hilaire-Saint-Florent « Le petit souper » } \\
\hline \multirow{3}{*}{$\mathrm{N}^{\circ}$ structure } & \multirow{3}{*}{$\mathrm{N}^{\circ} \mathrm{US}$} & \multicolumn{6}{|c|}{ Identification } \\
\hline & & \multicolumn{2}{|c|}{ Faune } & \multicolumn{2}{|c|}{ Humain } & \multirow{2}{*}{ Autre } & \multirow{2}{*}{ Degré crémation } \\
\hline & & Dent & Os & Dent & Os & & \\
\hline F 14 & Pas de $\mathrm{N}^{\circ} \mathrm{US}$ & & 3,76 & & & & blanc \\
\hline F 27 & US 1 & 0,51 & & & & & brun à blanchâtre \\
\hline \multirow{8}{*}{ F 37} & US 1 & 1,65 & 15,44 & & & & brun à blanchâtre \\
\hline & UE 101 & 1,37 & 15,13 & & & & brun à blanchâtre \\
\hline & UE 103 & 11,2 & 14,02 & & & & bleuté à blanchâtre \\
\hline & UE $103 \mathrm{fd}$ du crst central & & 0,74 & & & & brun à blanchâtre \\
\hline & Pas de $\mathrm{N}^{\circ}$ US & & 8,84 & & & & bleuté à blanchâtre \\
\hline & UE 100 & & 12,82 & & & & brun à blanchâtre \\
\hline & UE 103, empierrement & 0,29 & 4,64 & & & & bleuté à blanchâtre \\
\hline & US 2 & 5,56 & 6,2 & & & & bleuté à blanchâtre \\
\hline \multirow{5}{*}{ F 41} & Pas de $\mathrm{N}^{\circ}$ US & & & & & $\begin{array}{l}\text { cailloux } \\
\text { chauffé }\end{array}$ & blanc \\
\hline & US $2,1 / 4 \mathrm{SO}$ & & & & 0,7 & & blanc \\
\hline & Pas de $\mathrm{N}^{\circ}$ US & & & & 9,57 & & blanc \\
\hline & US $1, \mathrm{NE}$ & & & & 1,15 & & blanc \\
\hline & US 2 & & & & 2,85 & & blanc \\
\hline \multirow{3}{*}{ F 43} & US 2 & 5,02 & & & & & brun juste chauffé \\
\hline & Niv 4 & & 243,5 & & & & brun juste chauffé \\
\hline & UE 43 & 25,89 & 146,63 & & & & brun juste chauffé \\
\hline F 44 & US 1 & & & & 2,1 & & blanc \\
\hline \multirow{2}{*}{ F 62} & US 1 & & 2,84 & & & & brun à blanchâtre \\
\hline & US 9 & 0,1 & 56,04 & & & & bleuté à blanchâtre \\
\hline \multirow{3}{*}{ F 84} & US $1,1 / 2$ ouest & & & & 3,7 & & blanchâtre à blanc \\
\hline & US $1,1 / 2$ sud & & & & 0,1 & & blanchâtre à blanc \\
\hline & US $1,1 / 2$ est & & & & 2,5 & & blanchâtre à blanc \\
\hline F 88 & US 2 & 9,48 & & & & & brun à blanchâtre \\
\hline F 90 & US 1 & & & & 1,16 & & blanc \\
\hline F 91 & US $1,1 / 4 \mathrm{SO}$ & 3,13 & & & & & brun à blanchâtre \\
\hline
\end{tabular}

Tableau 1 : Le Petit Souper, nombre de restes (N.R.) et nombre minimum d'individus par structure (N.M.I.)

Table 1: Le Petit Souper, many rests (N.R.) and minimum number individuals by features. 
On remarque que les restes osseux sont peu nombreux dans les structures qu'ils soient d'origine humaine ou animale. Seules les fosses 37, 43 et 62 dépassent un poids de 50 grammes.

Aucune structure ne contenait les deux types d'ossements, On constate bien une différenciation dans l'utilisation des fosses.

\section{Les restes de faune}

Ils se composent de restes dentaires et osseux, généralement le degré de crémation va du blanchâtre au blanc pour certains fragments très brûlés, voire recuits. Cependant, pour la fosse 43 , les ossements sont juste chauffés, et cela évoque davantage des restes culinaires de même pour certains restes issus de la fosse 37.

\section{Les restes humains}

Les restes identifiés comme humains sont peu nombreux et concentrés dans quatre fosses. Ils sont très brûlés (coloration blanchâtre à blanche) et de petite taille (maximum $2 \mathrm{~cm}$ pour les plus gros fragments).

\section{Fosse 41}

14,27 grammes d'ossements comprenant des esquilles ainsi que des fragments de crâne, de tibia et de diaphyse de membre supérieur. Les ossements sont très brûlés (coloration blanche) et appartiennent vraisemblablement à un individu de taille adulte (pour les membres et le crâne).

\section{Fosse 44}

2,1 grammes d'ossements comprenant des fragments de diaphyse indéterminés et une extrémité distale de phalange de main (moyenne ou proximale, de rang indéterminé) de taille adulte (tête de la phalange est soudée sans ligne de fusion visible).

\section{Fosse 84}

6,3 grammes d'ossements comprenant des esquilles indéterminées, du crâne et des fragments de diaphyse dont du radius. L'épaisseur de la corticale du radius évoque un individu de taille adulte.

\section{Fosse 90}

1,16 grammes d'ossements comprenant un fragment de crâne et deux fragments de diaphyse indéterminés. Le fragment de crâne est très fin et évoque plutôt un individu immature.

En conclusion, les restes osseux retrouvés à Saint-Hilaire-Saint-Florent sont majoritairement d'origine animale et correspondent vraisemblablement pour la part la plus importante à des restes culinaires.

La présence de restes humains très brûlés est réservée dans quatre fosses sans mélange avec la faune. Malgré la faiblesse de l'échantillon pour ces dépôts, il semble bien y avoir là un geste spécifique et une volonté d'isoler ces restes humains. 


\section{Bibliographie}

Barbier, A., Boudin, R.-C., Chaix, L., Delibrias, G., Erroux, J., Lundström-Baudais, K., Passard, F., Pétrequin A.-M., Pétrequin, P., Picard, P., Piningre, J.-F., Rutlowski, H., SÉné, G., Urlarcher, J.-P. et Vuaillat, D., 1981 - La grotte des Planches-près-Arbois (Jura), Gallia Préhistoire, t. 24, fasc. 1, p. 145-200.

Blanchet, J.-C. et Talon, M., 2005 - L'Age du Bronze dans la moyenne vallée de l'Oise : apports récents, in Bourgeors, J., Talon, M. (ed.), L'Âge du Bronze du nord de la France dans son contexte européen, Actes des congrès nationaux des sociétés historiques et scientifiques, $125^{\mathrm{e}}$, Lille, 2000, Éditions du Comité des Travaux historiques et scientifiques, p. 227-268.

Blouet, V., Faye, O., Gebus, L., Mervelet, Ph. et Milutinovic, M., 1988 - Le gisement de Maizières-Les-Metz et la transition Hallstatt A1-Hallstatt A2 en Lorraine, in Brun, P. et Mordant, C. (dir.), Le groupe Rhin-Suisse - France Orientale et la notion des Champs d'Urnes, Actes du colloque international de Nemours, APRAIF, 1988 (Mémoires du Musée de Préhistoire d'Île-de-France n ${ }^{\circ}$ ), p. 193-200.

Bourson, V., 2006 - La céramique du Bronze final II b/III a dans le département du Jura. Approche typo-chronologique de trois sites : Choisey, Quintigny, Ruffey-sur-Seille, Revue archéologique de l'Est, t. 55, p. 7-65.|

Bouthier, A., Daugas, J.-P. et Vital, J., 1988 - La nécropole Bronze final des Vicreuses à Pougues-Les-Eaux (Nièvre) : bilan et perspectives, in Brun, P. et Mordant, C. (dir.), Le groupe Rhin - Suisse - France Orientale et la notion des Champs d'Urnes, Actes du colloque international de Nemours, APRAIF, 1988 (Mémoires du Musée de Préhistoire d’̂̂le-de-France $\left.\mathrm{n}^{\circ} 1\right)$, p. 417-424.

Buchez, N. et Talon, M., 2005 - L'âge du Bronze dans le bassin de la Somme, bilan et périodisation du mobilier céramique in Bourgeois, J. et Talon, M. (ed.), L'Âge du Bronze du nord de la France dans son contexte européen, Actes des congrès nationaux des sociétés historiques et scientifiques, $125^{\mathrm{e}}$, Lille, 2000, Éditions du comité des travaux historiques et scientifiques, p. 159-188.

Chancerel, A., Marcigny, C. et San Juan, G., 2006 - La double enceinte de l'âge du Bronze moyen de la ZI sud (Mondeville, Grentheville) in Chancerel, A., Marcigny, C. et GHesquière, E. (dir.), Le plateau de Mondeville (Calvados) du Néolithique à l'âge du Bronze. Documents d'archéologie française $n^{\circ}$ 99. Éditions de la Maison des sciences de l'Homme, Paris, 200 p.

Chertier, B., 1988 - Contribution à la notion des "Champs d'Urnes ». Le style céramique "Rhin-Suisse-France Orientale » et sa présence dans les nécropoles Champenoises, in BRUN, P. et Mordant, C. (dir.), Le groupe Rhin-Suisse-France Orientale et la notion des Champs d'Urnes, Actes du colloque interna- tional de Nemours, APRAIF, 1988 (Mémoires du Musée de Préhistoire d'Ile-de-France $\mathrm{n}^{\circ} 1$ ), p. 241-248.

Cordier, G., 2009 - L'Âge du Bronze dans les pays de la Loire Moyenne, Éditions de la Simarre, Joué-lès-Tours, 699 p.

Daugas, J.-P. et Vital, J., 1988 - Éléments du groupe RSFO dans le massif central français (Auvergne et orléanais), in BRUN, P. et Mordant, C. (dir.) - Le groupe Rhin-Suisse-France Orientale et la notion des Champs d'Urnes, Actes du colloque international de Nemours, APRAIF, 1988 (Mémoires du Musée de Préhistoire d'Île-de-France n ${ }^{\circ}$ 1), p. 425-434.

Ducreux, F., 2007 - Typo-chronologie des céramiques du groupe Rhin-Suisse-France Orientale (RSFO) dans la région dijonnaise : étude stratigraphique des dépotoirs de matériaux céramiques en contexte d'habitat sur le site du Pré-du-Plancher à Varois-et-Chaignot (Côte-d'Or) - Revue archéologique de l'Est, t. 56, p. 7-86.

Froquet, H., Castanet, C., Joly, S. et Pradat, B., 2006-2007 Une fosse du Bronze final II b dans le Val d'Orléans à Sandillon (Loiret) : données archéologiques et contexte environnemental, Revue archéologique du Centre de la France, t. 45-46, p. 1-23.

Gomez de Soto, J., Gruet, M. et Pautreau, J.-P., 1988 - La période du Bronze final II b-III a en Centre-Ouest, in Brun, P. et Mordant, C. (dir.), Le groupe Rhin-Suisse-France Orientale et la notion des Champs d'Urnes, Actes du colloque international de Nemours, APRAIF, 1988 (Mémoires du Musée de Préhistoire d'Île-de-France $n^{\circ} 1$ ), p. 517-524.

Gomez de Soto, J., Kerouanton, I., Boulestin, B. et Bourhis, J.-R., 1991 - La grotte du Quéroy à Chazelles (Charente) - Le Bronze final III, Bulletin de la Société Préhistorique française, t. 88, n' 10-12, p. 341-392.

Gruet, M., Roussot-Larroque, J. et Burnez, C., 1997 - L'Age du Bronze dans la grotte de Rancogne (Charente), Éditions RMN, Paris (Musée des Antiquités nationales, mémoire 3), 152 p., 53 pl.

JAN, E., 2006 - Guilly (Loiret), La Petite Guillerie (site 45-164-12), fosses dépotoir du début de l'Age du Bronze final II b, document final de synthèse de l'opération de sondage, Société archéologique et historique de Vienne-en-Val, $57 \mathrm{p}$.

Kimmig, W., 1988 - Les Champs d'Urnes d'Europe centrale. Remarques à propos du Colloque de Nemours, in Brun, P. et Mordant, C. (dir.), Le groupe Rhin-Suisse-France Orientale et la notion des Champs d'Urnes, Actes du colloque international de Nemours, APRAIF, 1988 (Mémoires du Musée de Préhistoire d'Île-de-France ${ }^{\circ} 1$ ), p. 11-15.

LHelgouach, J., 1979 - Circonscription des Pays-de-la-Loire, Gallia Préhistoire, t. 22, fasc. 2, p. 557-584.

Marcigny, C., Ghesquière, E., Clément-Sauleau, S., et Verney, A., 2005 - L'âge du Bronze en basse-Normandie : définition par le mobilier céramique, une première tentative, in Bourgeois, J. et Talon, M. (éd.), L'âge du Bronze dans le nord de la France dans son contexte européen, Actes du $125^{\mathrm{e}}$ congrès 
national des Sociétés historiques et scientifiques, Lille, 2000, Éditions du Comité des Travaux Historiques et Scientifiques, Paris, p. 303-332.

Mohen, J.-P. et Bailloud, G., 1987 - La vie quotidienne. Les Fouilles du Fort-Harrouard, Éditions Picard, Paris (L'Age du Bronze en France - 4), 243 p., 108 pl.

Mordant, C. et D., 1970 - Le site protohistorique des Gours-auxLions à Marolles-sur-Seine (Seine-et-Marne), Mémoires de la Société Préhistorique Française, t. 8, 138 p.

Muller, F., Roscio M., Auxiette, G., 2008 - Maillot « Les Terres de Terrier»(Yonne). Typo-chronologie d'un ensemble céramique du début du Bronze final, Revue archéologique de l'Est, p. 21-39.

Muller, F., Nicolas, T. et Auxiette, G., 2008 - La céramique Rhin-Suisse-France Orientale de Malay-le-Grand « Les Bas Musats " : un ensemble de la phase récente du Bronze final III a dans l'Yonne, Revue archéologique de l'Est, t. 57, p. 389-402.

Nicolas, T., 2007 - La série céramique du site de l'Alleu à SaintHilaire-Saint-Florent (Maine-et-Loire) : redécouverte d'un site du Bronze final II a-II b in De Saulce, A., Serna, V. et Gallicé, A., Archéologies en Loire, Actualité de la recherche dans les régions Centre et Pays-de-la-Loire (Aesturia, cultures et développement durable), p. 389-409.

Piningre, J.-F., 2005 - Un habitat de la fin de l'âge du Bronze : le site d'Inghem (Pas-de-calais), in Bourgeois, J. et TAlon, M. (dir.) L'áge du Bronze dans le nord de la France dans son contexte européen, Éditions du Comité des Travaux historiques et scientifiques, Paris, p. 137-158.

Pithon, M., 2006 - "Chemin du Petit Souper ", commune de Saint-Hilaire-Saint-Florent (Maine-et-Loire), Rapport de diagnostic archéologique, Cesson-sévigné, Inrap Grand-Ouest.

Roussot-Larroque, J., 1988 - Le "Rhin-Suisse-France Orientale " et l'Aquitaine, in Brun, P. et Mordant, C. (dir.), Le groupe Rhin-Suisse-France Orientale et la notion des Champs
d'Urnes, Actes du colloque international de Nemours, APRAIF, 1988 (Mémoires du Musée de Préhistoire d'Ile-de-France $\left.\mathrm{n}^{\circ} 1\right)$, p. 481-511.

Rychner, V., 1988 - Dendrochronologie du groupe Rhin-Suisse dans la région neuchâteloise, in Brun, P. et Mordant, C. (dir.) - Le groupe Rhin-Suisse-France Orientale et la notion des Champs d'Urnes, Actes du colloque international de Nemours, APRAIF, 1988 (Mémoires du Musée de Préhistoire d'Île-de-France $\left.\mathrm{n}^{\circ} 1\right)$, p. 125-129, 6 pl.

Salanova, L., 2000 - La question du Campaniforme en France et dans les îles anglo-normandes. Productions, chronologie et rôles d'un standard céramique, Paris, Société Préhistorique Française, Éditions du CTHS, p. 1-392.

Simonin, D., 1982 - Sites de l'Age du Bronze à Echilleuses et à la Neuville-sur-Essonne (Loiret), Revue Archéologique du Loiret, t. 8 , p. $25-47$.

Viau, Y. (dir.), Cabo, E., Forré, P. et Le Guévellou, R., 2008 "Le Petit Souper », commune de Saint-Hilaire-Saint-Florent (Maine-et-Loire). Rapport de fouille archéologique, Cessonsévigné, Inrap Grand-Ouest.

Vital, J., 1986 - La grotte des Cloches à Saint-Martin d'Ardèche, Bulletin de la Société préhistorique française, t. 83, n 11-12, p. $503-545$.

Vital, J., 1990 - Protohistoire du défilé de Donzère. L'âge du Bronze dans la Baume des Anges (Drôme), Documents d'archéologie Française $n^{\circ} 28$, Éditions de la Maison des Sciences de l'Homme, Paris, p.1-145.

Villes, A., 1988 - Du Bronze final I b au Bronze final III a dans le secteur de la Loire moyenne, in Brun, P. et Mordant, C. (dir.) - Le groupe Rhin-Suisse-France Orientale et la notion des Champs d'Urnes, Actes du colloque international de Nemours, APRAIF, 1988 (Mémoires du Musée de Préhistoire d'Ile-deFrance $\left.n^{\circ} 1\right)$, p. 383-415. 